\title{
La educación de un arquitecto en primer año: La malla de los nueve cuadrados y Architectonics de la Cooper Union.
}

\section{Education of an architect in first year: Nine- square grid and Architectonics of the Cooper Union.}

Oscar Mauricio Pérez Fernández

Universidad La Gran Colombia, Colombia

oscar.perez@ugc.edu.co

https://orcid.org/0000-0002-5902-5101 


\title{
Resumen
}

La malla de los nueve cuadrados, el famoso ejercicio de John Hejduk, ha sido el proyecto más replicado del curso Architectonics de la Cooper Union. Este recurso pedagógico ha sido reproducido en diversas universidades del planeta. Esto puede deberse a la facilidad en su reproducción material, sin embargo, el ejercicio contiene un contexto conceptual preciso que acompaña a sus elementos; los estudios de Colin Rowe y Robert Slutsky sobre las relaciones entre la historia de la arquitectura y la formulación del lenguaje visual desarrollado a partir del arte y el diseño de vanguardia del siglo XX. Este ejercicio se presenta en un espacio abstracto, desprovisto de escala y función, que permite el análisis y la especulación espacial. El objetivo de su estudio se basa en el reconocimiento y la comparación, otras visiones de la clase de Arquitectura después de malla de los nueve cuadrados, revisando ejercicios de arquitectos como Raimund Abraham, Elizabeth Diller, Anthony Candido y Chester Wisniewski y descubrir las persistencias y variaciones en cada caso. Esto a partir de las dos principales publicaciones de trabajos de estudiantes que han salido de Cooper hasta la fecha: Educación de un Arquitecto 19641971 y Formación de arquitecto 1972-1985.

Palabras clave: lenguaje visual; análisis arquitectónico; diseño arquitectónico; teoría de la arquitectura; proceso de aprendizaje

\begin{abstract}
The nine-square grid, John Hejduk's famous exercise, has been the most replicated project of the Cooper Union Architectonics course. This pedagogical resource has been reproduced in various universities in the world. This can be for the ease of its material reproduction; however, the exercise contains a precise conceptual context that accompanies its elements; Colin Rowe and Robert Slutsky's studies about the relationships between the history of architecture and the formulation of visual language developed as early as the avant-garde art and design of the twentieth century. This exercise is presented in an abstract space, devoid of scale and function, which allows analysis and spatial speculation. The objective of his study is based on the recognition and comparison of other visions of the Architecture class after the nine square problem, reviewing exercises of architects such as Raimund Abraham, Elizabeth Diller Anthony Candido and Chester Wisniewski and discovering the persistence and variations in each case. This begins with two main publications of students work from the Cooper: An Architect Education 1964-1971 and Architect Training 1972-1985.
\end{abstract}

Keywords: visual language; architectural analysis; architectural design; architecture theory;

\section{learning process}

\section{Para citar este artículo / To cite this article:}

PÉREZ FERNÁNDEZ, O.M. La educación de un arquitecto en primer año: La malla de los nueve cuadrados y Architectonics de la Cooper Union. En: [i2] Investigación e Innovación en Arquitectura y Territorio [en línea]. 2021, Vol. 9, Núm. 2, pp. 75-106. ISSN: 2341-0515. https://doi.org/10.14198/I2.17697

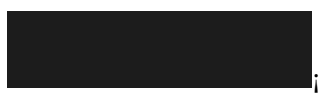




\section{Architectonics}

De acuerdo con la información aportada por Shantunu Bhalla (Bhalla,2018:12), desde la actualización en 1983, la definición del curso de Architectonics 111, no ha variado; se trata de "una introducción al estudio de la arquitectura investigando las relaciones del espacio, la estructura y la composición visual. Es una exploración de la sintaxis de la arquitectura, de sus modelos y su dibujo de proyecciones ortogonales" (Cooper Union, 2021: 49). Esta definición, desarrollada por Abraham, Diller y Wisniewski ha contado con varias interpretaciones de acuerdo con el enfoque de sus profesores titulares. Este artículo está dedicado al estudio de este curso en dos momentos a través de sus publicaciones Education of an Architect: A point of View. The Cooper Union School of Art \& Architecture 1964-1971 y The Irwin S. Chanin School of Architecture of the Cooper Union 1971-1985. El primer momento está definido por el Problema de La Malla de los 9 Cuadrados, que ha tenido una enorme influencia en programas internacionales de arquitectura, y que en la Cooper Union funcionó del año 1964 al año 1978 de acuerdo con las comunicaciones con el archivo de esta universidad. Este ejercicio, sin embargo, ha contado con una variada revisión en la última década a través de textos que señalan su importancia como ejercicio pedagógico introductorio de la arquitectura. En 1985, John Hejduk afirmó que la malla de los nueve cuadrados es uno de los problemas clásicos y abiertos, que se han dado en los últimos 30 años, es interminable en este vacío y por lo que es básicamente metafísico en esta misma entrevista Hejduk afirma que no quiere enseñarlo más, aunque puede. Las razones de la desaparición de este ejercicio para el curso de Architectonics son un misterio, de acuerdo con la comunicación con la Cooper Union el problema reaparece en niveles avanzados como tesis, siendo fantasma dentro de la escuela que circunda los pasillos e incluso la arquitectura del antiguo edificio y la remodelación propuesta por Hejduk como ya se ha notado (Estrella,2020).

La segunda fase de Architectonics presenta una amplia variedad de ejercicios propuestos por Anthony Candido, Chester Wisniewski, Raimund Abraham y Elizabeth Diller. Estos ejercicios presentan diferentes visiones entorno a las posibilidades de aprendizaje y exploración espacial y conceptual en primer año. Cada uno plantea un contraste en su manera de abordar temas de lenguaje espacial y esto se evidencia en temas como la estructura, la geometría y los materiales empleados revelando los enfoques disciplinares de cada uno de los profesores y así mostrando como afirman Lewis y Diller (1988: 9) que "la memoria colectiva del lugar siempre está esperando a los mineros, que no solo crean el nuevo tema, sino que investigan la raíz de su visión particular de fuertes principios".

El objetivo de este texto radica en revisar el curso de Architectonics, como una herramienta fundamental para introducirse a la exploración conceptual y sintáctica del primer año, hay que anotar que el ejercicio de la malla de los 9 cuadrados tuvo una duración en el programa de 12 años, mientras que los ejercicios presentados posteriormente no superan los 3 años de aplicación, de esta manera, el articulo esta divido en dos fases, Architectonics 64-71 y Architectonics 72-85. 


\section{Estructura y principios}
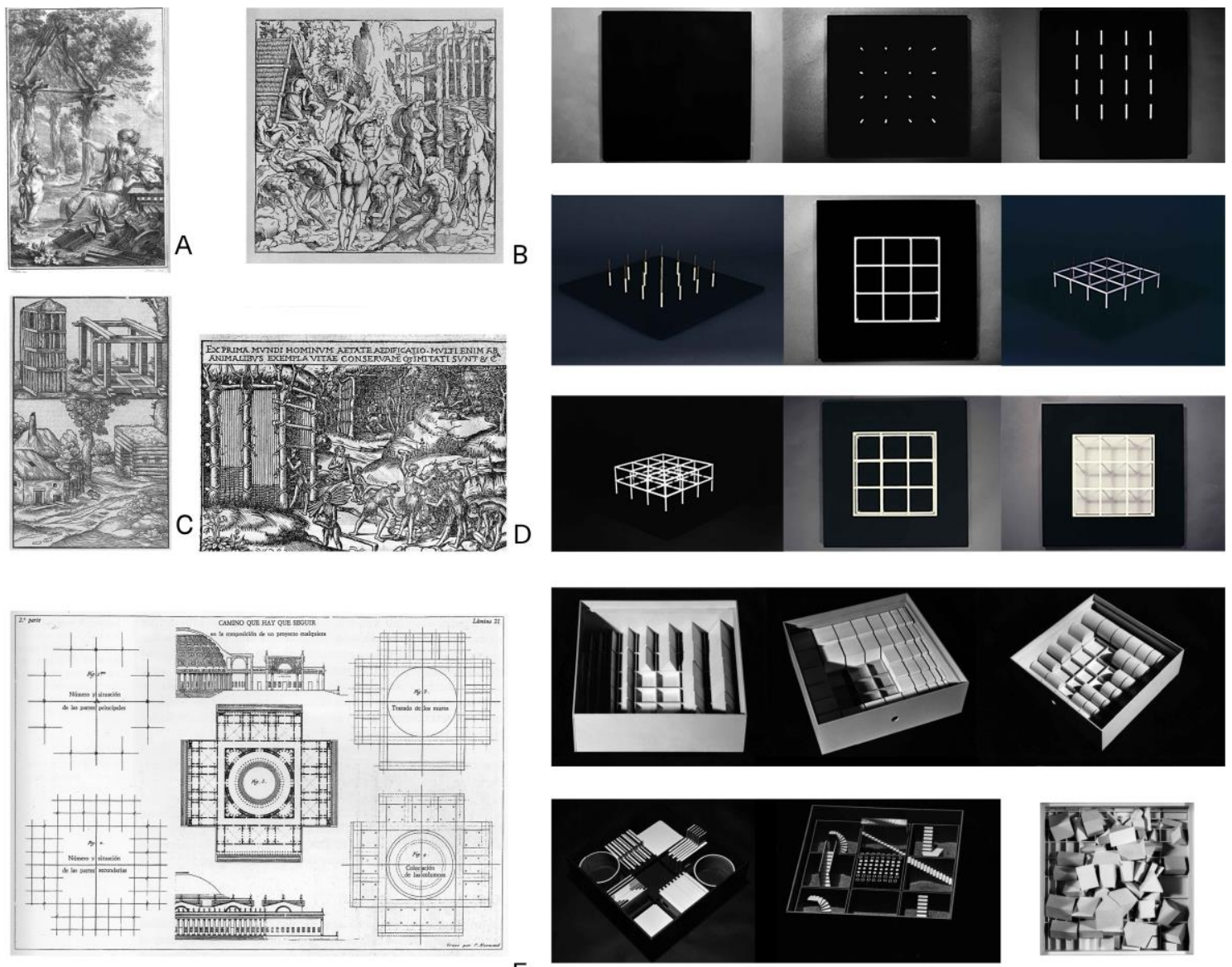

$\mathrm{E}$

Fig. 1. Algunas interpretaciones del origen de la arquitectura: [Grupo 1-izquierda] A. La Cabaña Primitiva (Laugier, 1753); B. Representación de la cabaña original (Martin, 1553); C. Cabaña Primitiva (Rivius, 1948); D. La Cabaña Primitiva (Cesariano, 1521); E. Camino que hay que seguir en la composición de un proyecto cualquiera (Durand, 1805). [Grupo 2-derecha] Secuencia de partes y despiece del kit de partes del Problema de la Malla de Los Nueve (Cooper Union 1976-77).

En algunos tratados de arquitectura como se evidencia en el Grupo 1, existe una profunda relación con el cuadrado, la cabaña primitiva suele ser relacionada con la materialización de un espacio abstracto, donde a través de cuatro parales o árboles se forma un cubo. Cabe resaltar que en la naturaleza existen algunas aproximaciones a la figura del cuadrado, sin embargo, teóricos concuerdan en que el cuadrado es realmente un logro humano (Consuegra,1992). Esto explicaría la presencia arquitectónica del cuadrado como sistema de medida y de habitación primitiva. Como se muestra en la presentación del kit de la malla (Grupo 2), desarrollado por la arquitecta Lorna McNeur (1977), se produce una clasificación de elementos que está presente en la tradición de la tratadística europea. Como precisa Christof Thoenes (2011:11) "Los restos de la arquitectura clásica debían estudiarse como textos; había que atribuir unos fragmentos a otros, reconstruir lo perdido y reconocer el original tras los añadidos posteriores y las deformaciones. La historia del lenguaje proporcionaba los modelos para comprender los estilos". Esta tradición implicó también la disección de edificios, a través del estudio de las ruinas, ejemplo de esto fueron 
las numerosas interpretaciones del tratado de Vitrubio ya que el documento original no contaba con imágenes. La labor de los arquitectos tratadistas, fue reconstruir el canon clásico a través de dibujos y clasificaciones.

Un antecedente de este ejercicio se puede encontrar en la École Polytechnique Nicolas Louis Durand (Fig. 1) en su Compendio de Lecciones de Arquitectura (1802 - 1805) , la primera parte de este libro está dedicada a los Elementos de los Edificios siendo consecuente con los procesos de clasificación presentes en tradición tratadística y la segunda parte está dedicada a su innovador sistema compositivo, una mecánica que explicaba posibilidades para la "combinación de elementos y composición de los edificios", lo cual buscó hacer "fácil y eficiente" la labor de diseño a través de la combinación de elementos básicos como columnas, muros y escaleras. Durand, elaboró un tratado fundacional en el tema de la composición arquitectónica, separó la arquitectura en los elementos y las partes constitutivos y desarrolló un inventario de posibles organizaciones, a través de una retícula cartesiana buscando ver la historia como un repositorio de estructuras organizativas, las cuales serían susceptibles de adaptación a través del estudio de los principios de composición.

Si en lugar de ocuparnos de hacer proyectos nos ocupáramos primero de los principios del arte, si nos familiarizáramos después con el mecanismo de la composición, podríamos hacer con facilidad, incluso con éxito el proyecto de cualquier edificio que se nos plantee sin haber hecho antes ningún otro (Durand, 1981).

Hay que tener en cuenta que el kit de partes de la malla de los nueve fue realizado en el año 1976, año en que se deja de enseñar para el curso de Architectonics. Este kit construido por McNeur coincide con la clasificación establecida en la tratadística europea, cada elemento de la malla es expuesto de manera aislada y cargado de un aura a través de las fotografías. En el año 1983, McNeur (1983: 24) establece su propia definición de la malla como "Un descubrimiento de la sencillez de los elementos singulares que componen el misterioso tejido de la arquitectura". En este mismo texto, la arquitecta menciona que aun cuando este ejercicio ha tenido varias interpretaciones en universidades de Estados Unidos y Canadá, pocos reconocen la malla de los nueve como una estructura reduccionista, la intención del curso de Architectonics es la examinación de los conceptos singulares, los órdenes y los elementos de la arquitectura. Para McNeur, el ejercicio es una abstracción de la arquitectura. "Abstracción es la identificación de esas estructuras presentes en cualquier condición que son esenciales para su existencia. La Abstracción es la esencia de la realidad. Extraer la esencia de muchos estilos de arquitectura, por la identificación de estas estructuras que son comunes a todas ellas, es abstraer la arquitectura" (McNeur, 1981:24). 
Existen profundas coincidencias entre la mecánica de composición de Durand, y el ejercicio de la malla de los nueve cuadrados, ambos son metodologías de síntesis para la arquitectura y ambos parten de un interés en concebir la arquitectura como un lenguaje con elementos que se repiten a lo largo de la historia, y ambos emplean la retícula como un elemento base de organización para plantear la composición arquitectónica. La retícula es el elemento ordenador que dispondrá los ejes de localización de los elementos, la base para el estudio del orden y la relación de los elementos.

Otra raíz de malla como estructura compositiva se encuentra en los textos Las Matemáticas de La Vivienda Idealy Transparencia Literal y Fenomenal el primero escrito por Collin Rowe y el segundo escrito por Collin Rowe en compañía de Robert Slutski. Hay que anotar que estos autores formaron parte del contexto que dio origen a la malla desde la universidad de Texas en los años 50 y que las indagaciones de estos textos presentan un antecedente clave para entender las raíces, y posibilidades del ejercicio. Esta visión presente en las vanguardias de comienzos de siglo XX, se basa en la comprensión del plano pictórico como realidad presentada, más que como una representación de la realidad, y una estructura compositiva en sí misma. La malla asumida desde el neoplasticismo, el cubismo y el purismo permite el uso de planos sucesivos dentro de un plano pictórico, en estos ejercicios espaciotemporales se aplana la visión de la realidad y a través de un espacio paralelo, que permite una visión simultánea de múltiples realidades, este recurso ha sido recientemente definido como estratificación espacial por Sonia Delgado Berrocal (2016). 

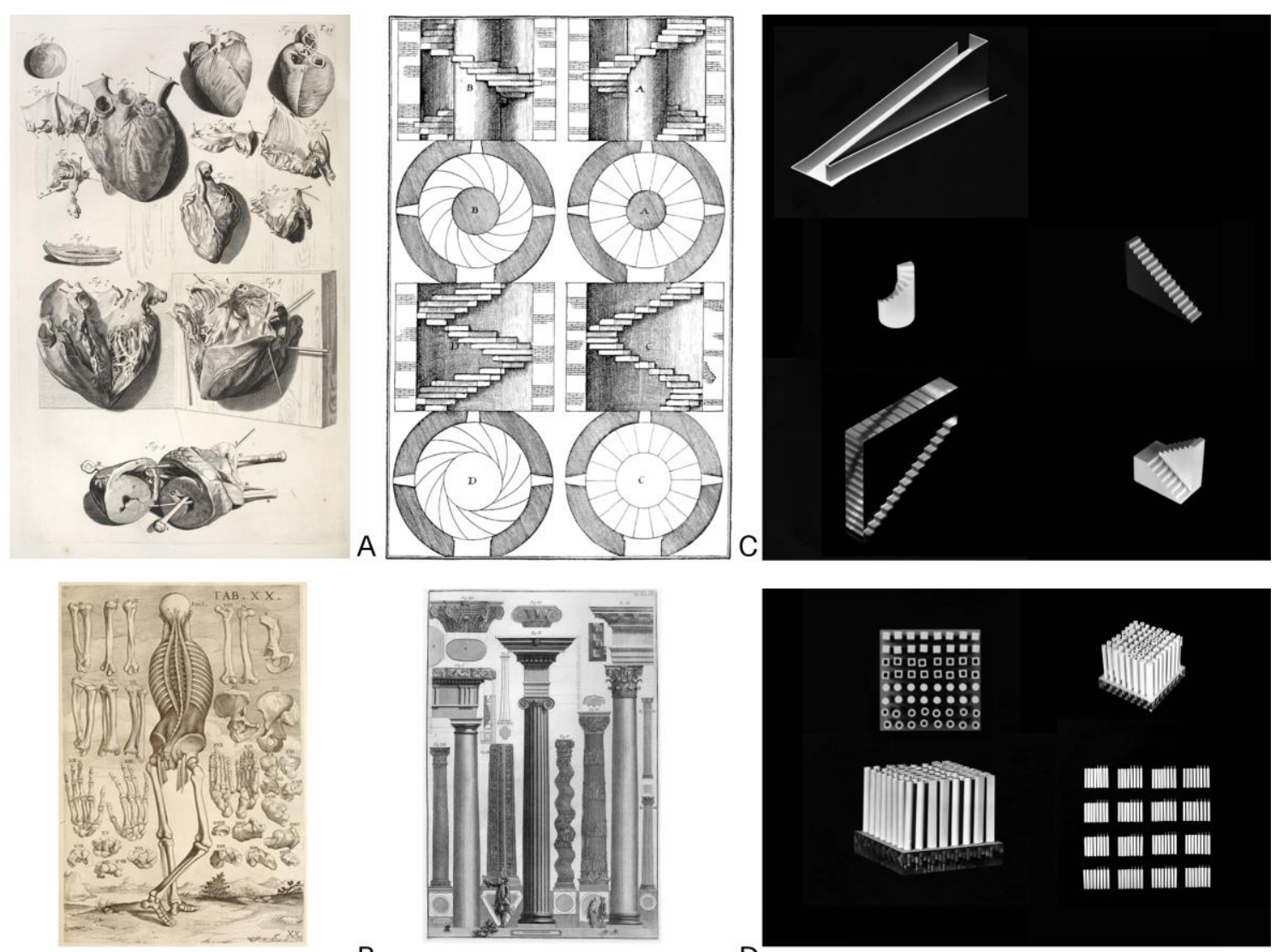

B

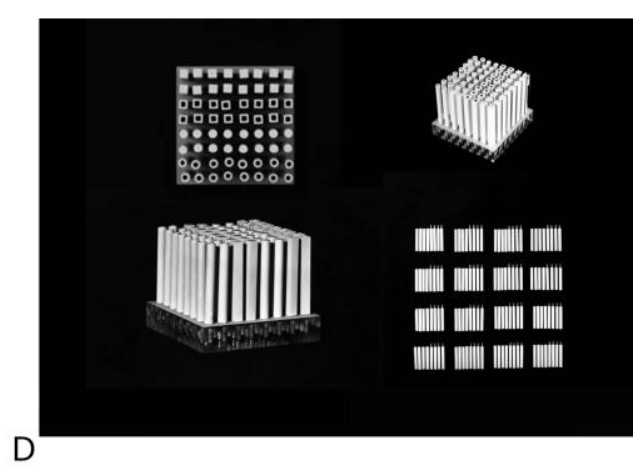

Fig. 2. [Grupo 3-Izquierda] A. Anatomia Humani Corporis, Centum \& Quinque Tabulis - Govard Bidloo, 1685. B. Pietro Berrettini da Cortona tabla XX Tabulae anatomicae; C. Escaleras en Andrea Palladio, Five Orders of Architecture 1570; D. Columnnas de la arquitectura griega Giovanni Battista Piranessi. [Grupo 4-derecha] Detalles de escaleras y columnas usadas en el kit de partes de la malla de los nueve. 

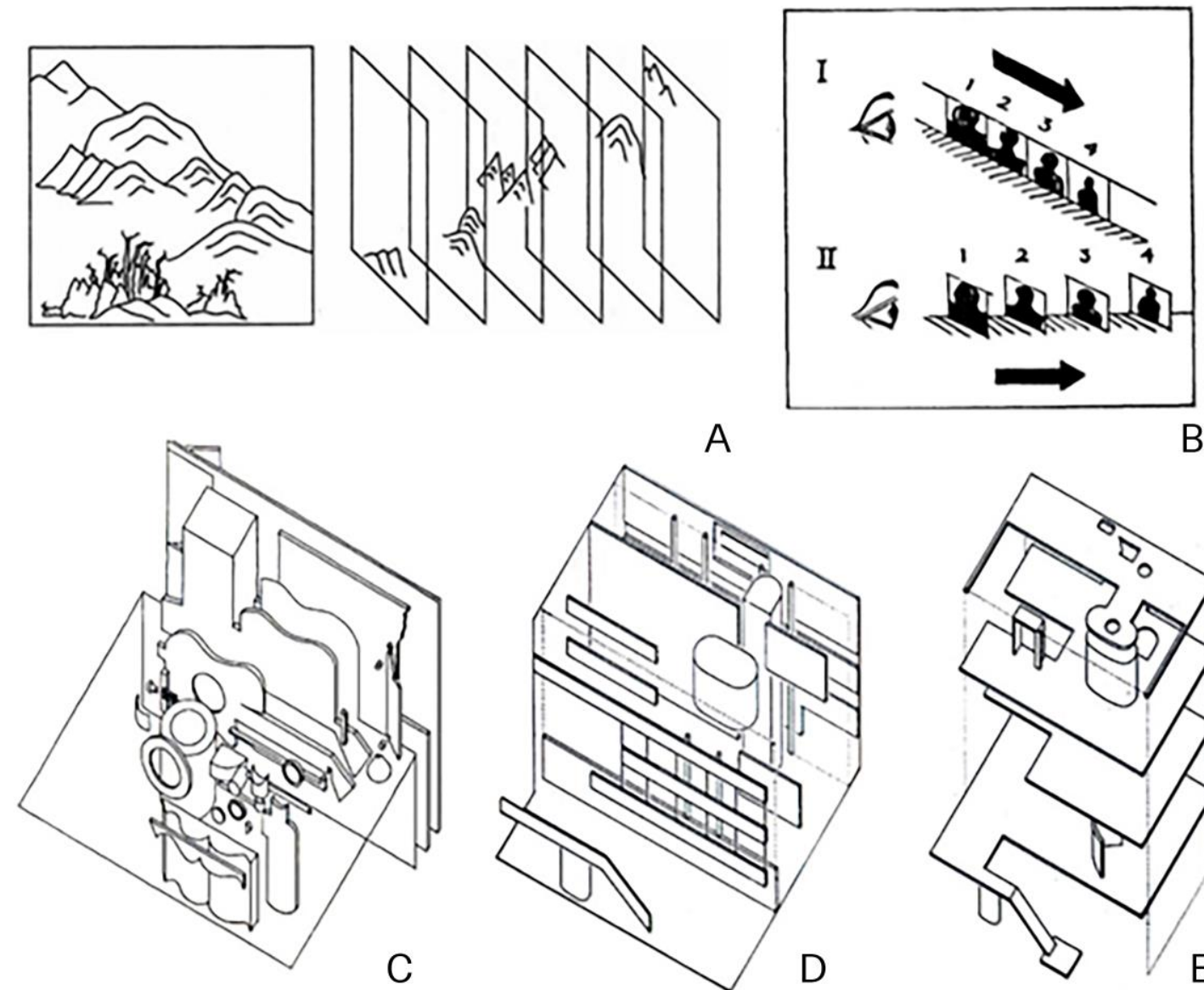

A

B

C
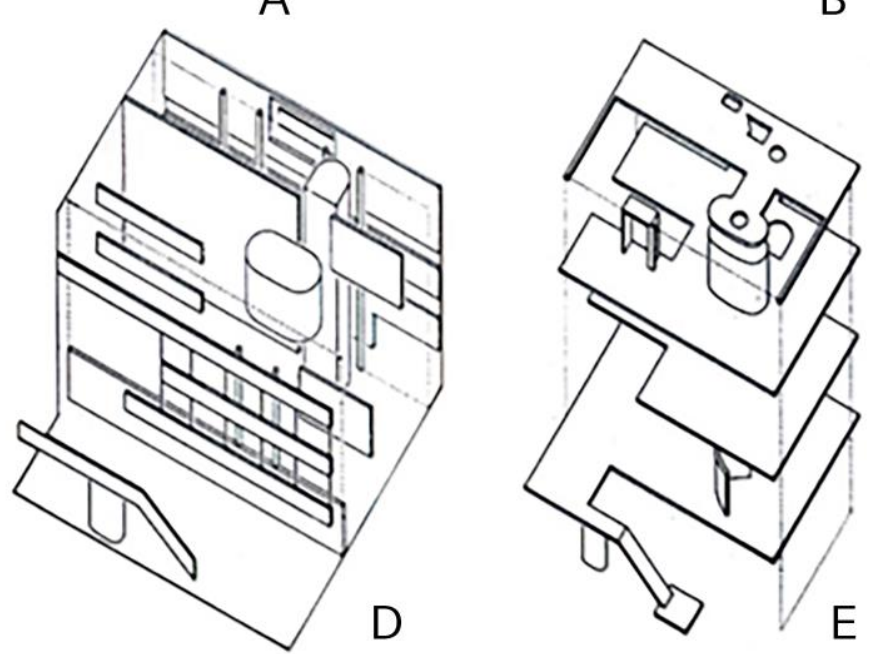

Fig. 3. A. Diagramas de la superposición de montañas de la pintura de Li-Sheng, Dream Journey through the Xiao and Xiang Rivers, (ca.1170). B. Eisenstein, Sergei: Esquema de percepción sobre la profundidad C. Descomposición, en una serie de planos paralelos, del cuadro Nature morte à la pile d'assiettes, 1920, de Le Corbusier. D. Descomposición vertical, en una serie de planos paralelos, de la Villa Garches. E. Descomposición vertical, en una serie de planos paralelos, de la Villa Garches F. Descomposición vertical, en una serie de planos paralelos, de la Villa Garches. Le Corbusier y la construcción vertical del espacio estratificado (Delgado Berrocal, 2016).

La división espacial formada por la malla compositiva implícita del cubismo permite la multiplicidad de puntos de vista, expandiendo y comprimiendo el plano dependiendo de la intención compositiva. Esta multiplicidad vista es desarrollada a partir del concepto de la transparencia fenomenal, que busca la comprensión de la experiencia arquitectónica como una secuencia donde, el espacio se ve y se intuye mediante una sucesión de acontecimientos. Como advierten Rowe y Slutzky (1980: 168) “la supresión de la profundidad, la contracción del espacio, la definición de los focos de luz, el adelantar los objetos, la paleta limitada, las retículas oblicuas y rectilineas, la tendencia al desarrollo periférico, todas éstas son características del cubismo analítico". 
El espacio fluctúa, a través de la transparencia fenomenal y se presta para la especulación del observador, cada movimiento entre estratos espaciales genera un momento entre la posibilidad del edificio y la materialización presentada. Las presentaciones de objetos frontalmente alineados producen una sucesión de planos acumulativos, cada plano se convierte en un momento de abstracción concreta. Como precisa Rowe, el plano es completo y fragmentario a la vez, rompe con el filo del muro o la columna, pero es a su vez armónico a través de la incorporación de un sistema de modulación dado por una secuencia métrica. "El observador hace posible penetrar en un espacio estratificado definido por planos reales o por sus propias proyecciones imaginarias y hace posible experimentar los conflictos de un espacio explícito y un espacio implícito" (Rowe y Slutzky, 1980:166)

"La arquitectura también tiene que ver con el sonido, pero no con el sonido pragmático sino con un sonido sobrenatural, un sonido del alma. Uno puede ser un buen constructor, hay gente que hace buenos edificios hoy en día, pero la tarea del arquitecto consiste en capturar esa atmósfera. La arquitectura es espacial no sólo porque en ella sea central el problema pragmático de la disposición de los espacios. Es la co-correspondencia de algo, es espacio, que básicamente es aire, traducido a tu espacio interior, que también es aire. Tiene que ver con situaciones extrañas relativas a la fluidez. Por ejemplo, en Oslo, cuando se levanta la niebla por la noche, prácticamente puedes cortar un cubo de aire con un cuchillo" (Hejduk, 1992: 80).

La métrica, la co-correspondencia de algo, que básicamente es aire, la vida de los edificios depende de la correlación entre su espacio y el aire interior de la persona. Entre la experiencia acumulada de la persona en concordancia u oposición al plano de lo real del edificio. Esta corporeización de la experiencia es enunciada reiteradamente por Rowe en sus textos expresados a través de fenómenos espaciales, que se conectan y se activan orgánicamente con el espacio interior de la persona, su intuición expresada por medio de la secuencia espacial. Estos son los temas que surgían en el contexto que dio origen a la malla de los nueve cuadrados.

\section{La proyección ortogonal}

Otro aspecto presente en la definición de Architectonics y de la malla de los nueve es la proyección ortogonal, este medio de proyección está presente en las primeras series de casas de John Hejduk (1954-1967), pero en general se volvió un rasgo distintivo de su obra denominándose Perspectiva Hejduk o Perspectiva de Grado Cerro (Allen, 2019). La proyección ortogonal, a escala y en verdadera magnitud, a diferencia de la deformación causada por la perspectiva, permite una visión de forma paralela de la totalidad del espacio logrando la alineación de elementos para crear efectos espaciales. Hejduk evidencia en la axonometría un instrumento para desarrollar la estratificación anteriormente señalada, y un medio de experimentación a través del manejo de la rotación de los ejes compositivos como se evidencia en las Casas Diamante (1962-1967). 
Existe un atributo presente en la axonometría y es conocido como su reversibilidad, en el cual a través de su condición de paralelismo el primer plano y el ultimo son intercambiables. Germán Martínez (2000) ${ }^{1}$, expone desde su punto vista las consecuencias de esta condición:

“(..) Cultural e históricamente estamos muy metidos dentro de la idea de perspectiva. Nosotros pensamos en perspectiva, y al pensar en perspectiva, quedamos clavados en un punto, y no vemos ni aquí, ni allá, ni del otro lado, ni quien nos está dando un palazo por la espalda."

La perspectiva representa de donde está el infinito y nosotros no estamos en el infinito, el infinito es allá. Para los japoneses nosotros vivimos en el infinito, porque al ser finitos, formamos parte y colaboramos con la creación del infinito, entonces a través de la meditación, del zen, puedo estar en cualquier sitio al mismo tiempo. Si nosotros cogemos una axonometría japonesa, en un cuadro japonés, yo sé que, si la continuo voy a ver todo el universo, y esa es la idea detrás de la pintura japonesa, por eso es por lo que yo veo cada parte al mismo y con la misma intensidad y la misma claridad. Los japoneses, les quitan el techo a las casas para ver lo que está pasando adentro, entonces la diferencia entre lo oriental y lo occidental es que ellos no se impiden del infinito y a nosotros nos toca dibujar el infinito para no verlo.

Cuando nosotros hacemos este tipo de ejercicios, lo que estamos tratando es que el estudiante comience a construir lo inconstruible, que él pueda construir vacío. Cuando él puede construir vacío entonces puede ver vacío y empieza a quitársele ese problema occidental de que hay cosas que no ve, él debe empezar a darse cuenta de que él ve todo. (Martínez, 1997)

La axonometría aplana la visión tridimensional causada en la deformación de la perspectiva producida por el cono óptico, y permite organizar simultáneamente el dibujo. A través de la axonometría se crea un espacio para alinear los diferentes elementos tanto en el sentido X e Y como en el sentido Y y Z. Esta condición del dibujo reitera la existencia de un marco fijo resultante en la malla como base del ejercicio frente a su posibilidad de variación en cada nuevo ejercicio que se presenta como una capa adicional, el dibujo axonométrico se vuelve un medio para articular dimensionalmente los elementos. Como precisa Rafael Moneo (1980), el objeto, ya real en su condición bidimensional que el dibujo le confiere, deja trascender su espacialidad, sin perder a su vez aquella tridimensionalidad característica de la arquitectura.

\section{Los límites de la malla}

De acuerdo con la experiencia de Germán Martínez como exalumno de la Cooper Union, la malla de los nueve cuadrados funciona como un modelo para aproximarse a la arquitectura, ya que aun cuando no existe una obligación funcional o contextual, existe un primer acercamiento al programa arquitectónico ya que el estudiante trabaja sobre límites

${ }^{1}$ La malla de los nueve. Conferencia dictada en la Universidad Católica de Colombia 
bien definidos, esto implica que el estudiante no debe referirse a otras condiciones distintas a las impuestas en cada ejercicio. En la malla de los nueve tampoco existe una obligación frente a la escala, las indicaciones de Hejduk para la malla incluyen medidas para la construcción de la maqueta, pero no tiene una escala, y al no tener escala permite que el estudiante especule en cuanto a las posibilidades del ejercicio. "La escala es algo importante de entender y el algo importante de contradecir, el estudiante puede comenzar a ver lo grande como pequeño y lo pequeño como grande" (Martínez(1997) ${ }^{2}$. Al no trabajar con una escala definida para el ejercicio se permite que el objeto tenga múltiples lecturas, así como opciones de ocupación del espacio. En los ejercicios de la malla se enfatiza en las relaciones entre elementos arquitectónicos y los espacios resultantes dentro de un marco controlado. Este marco proporciona un espacio ilimitado, existen elementos que se pueden agregar a este marco, y los atributos vienen definidos por reglas o problemas. Según Moneo (1980), no existe una solución dada o un óptimo, su razón de ser es la carga académica que comporta, el ejercicio funciona como un laboratorio en el cual no existe un proyecto terminado, sino ensayos con los diferentes elementos y las relaciones planteadas por el profesor.

Estos ensayos se exponen de manera colectiva a través del curso, cada estudiante genera una interpretación del ejercicio aproximándose al lenguaje arquitectónico. La experiencia de aprendizaje que se deriva del proceso de trabajo colectivo, el cual da lugar la alineación o la coincidencia de intensiones espaciales entre los proyectos de los estudiantes, el aula de clase permite también la simultaneidad de resultados, hay caminos o contrapropuestas de los estudiantes probando variaciones a los ejercicios planteados. "El tiempo de cada ejercicio es de una semana, la maqueta se produce el fin de semana y se dibuja durante la semana, durante todo un año y por la repetición durante todo año, y el posible agotamiento se producen reacciones de los estudiantes en contra la malla, es importante que se den estas reacciones ya que se convierten en una forma de critica a las posibilidades del ejercicio trayendo nuevas temáticas al ejercicio" (Martínez, 1997) ${ }^{3}$.

El fin último de la malla radica en la puesta de trabajo sobre el concepto de estructura ya sea física o secuencial como se ha anotado, representa la idea de orden, en su sentido más elemental. El ejercicio tiene como objetivo la visualización de posibilidades para la arquitectura, para así incluir estratos a una estructura espacial primaria. La repetición de la retícula es la base del ejercicio, este se da primero a través de cada módulo o secuencia de la malla y a través de la reiteración de esta en los sucesivos ejercicios. Como menciona Søberg (2012) examinando el concepto de repetición presente en la obra arquitectónica, analítica y poética de John Hejduk, la estructura, o lo que consideramos estable tiene la capacidad de cambiar; la utilización de la retícula visual permite trabajar a partir de la persistencia de imágenes en la memoria, cada lectura funciona como una re-creación de la secuencia basada en que lo repetido crea otra condición que enmascara aquello que significa.

\footnotetext{
${ }^{2}$ La malla de los nueve. Conferencia dictada en la Universidad Católica de Colombia 
En el libro de la Cooper Union (1971) existen dos definiciones para el problema de la malla de los nueve, una desarrollada por John Hejduk y otra por Robert Slutski. De estas definiciones se puede inferir que en el caso de Hejduk existe un enfoque mucho más arquitectónico, centrado en la definición de los elementos, los cuales no tienen diferenciación como elementos físicos (rejilla, marco, poste, dintel, panel) sino también relacionales (centro, periferia, campo, borde, linea, plano, volumen, extensión, compresión, tensión, corte, etc.). También de la significación del dibujo arquitectónico expresado a través de sus principales vistas (plano, elevación, sección, detalles) y a través de ejercicios se da una primera idea de fabricación. El ejercicio se plantea de una forma abierta, teniendo claro, los elementos de la arquitectura como un lenguaje que se expresa a través de palabras y dibujos precisos.

En el libro posterior a la exposición del MoMa de la Cooper Union, Education of An Architect, The Irwin S. Chanin School (Hejduk y Henderson, 1988) se presenta solamente la malla de los nueve cuadrados en las primeras tres primeras páginas. En la primera página aparece una planta que abre el capítulo de primer año, la malla es presentada a modo de exlibris, seguido de una serie de recortes del diccionario con las palabras "beam", “column", "pan'el", "pier", “Wall”y "fab'ri-cate”en el centro. Los elementos más básicos y primigenios de la arquitectura, interpretados en su máxima abstracción. En el centro de la diagramación se encuentra la palabra "fab ricate, fabricar: construir, frame, edificio, hacer". El mismo concepto con el que Hejduk cerraba su definición.

En la siguiente página encontramos un despiece de los elementos de la malla, cuidadosamente ordenados y catalogados en sus respectivas cajas. Las escaleras, los diferentes tipos de columnas, los paneles acomodados de acuerdo con un sistema modular, al igual que los sólidos, organizados de mayor a menor. La visión de las notas de Hejduk está materializada, catalogada y encajada. La malla de los nueve regresa en esta publicación, pero ya no a partir de definiciones de sus autores, sino la malla misma como una definición de la arquitectura, como la abstracción de sus elementos esenciales.

Desde la publicación del primer libro en el año 1971, han pasado casi 15 años, esta nueva edición de trabajos de la Cooper Union presenta un contexto disciplinar distinto a las exploraciones del cubismo y la reinterpretación de las vanguardias de comienzos de siglo en su lugar tenemos los finales de los años 70 y los inicios de los años 80 , que pertenecían a una época marcada por la contracultura, el arte conceptual y el auge de la de-construcción del lenguaje como una estrategia "para reorganizar de cierto modo el pensamiento occidental, ante un variado surtido de contradicciones y desigualdades no lógico-discursivas" (Borges de Meneses, 2013: 178). Se buscaba cuestionar lo tradicional, presente en las instituciones y así mismo en los discursos disciplinares evidenciado de esta forma las fisuras latentes en lo convencional. De ahí que estos ejercicios planteen otros ordenes presentes en lo excéntrico y lo irresuelto, en contraposición a la simetría ortogonal presente en la malla de los nueve cuadrados. 


\section{El ejercicio de Ledoux - Raimund Abraham}

El primer ejercicio planteado por Raimund Abraham utiliza la obra de Claude Nicolas Ledoux, en lo que se define como un ejercicio que en palabras de Abraham "se aleja de un purismo autoconsciente por las formas geométricas aparta radicalmente de la convención de un análisis histórico"(Abraham, 1988: 14) Estableciendo un proceso de evolución en varios niveles de interpretación y organizándose a través de seis fases:

(i) La significación de la arquitectura como una manifestación únicamente de dibujo

(ii) La reducción de proposiciones altamente simbólicas y visionarias proposiciones en la construcción elemental de la geometría

(iii) De-composición y re-clasificación de elementos arquitectónicos

(iv) Documentación a través de proyecciones ortogonales. Reconocimiento de relaciones geométricas específicas

(v) Traducción de proposiciones geométricas en maquetas

(vi) Composición y deconstrucción de modelos a mediante una clasificación sistémica de los componentes arquitectónicos elementales

Para comenzar, Abraham establece que la arquitectura se construye a través del concepto de anticipación, su obra se basa en dibujos que expresan una materialidad y las condiciones propias de la arquitectura, a partir de estos se puede leer el peso de la estructura y las condiciones propias que la componen:

"Como arquitecto es muy importante que distingas entre diferentes realidades. Está la realidad del dibujo y la realidad del edificio. Entonces se podría decir, o al menos es la creencia común de que la arquitectura tiene que construirse; Siempre lo he negado, porque en última instancia se basa en una idea. Nunca necesito un edificio para verificar mi idea. Por supuesto, lo que pasa con un edificio es más su vanidad y su experiencia física real. Pero anticipo; Ni siquiera lo construiría si no pudiera anticipar cómo sería." (Abraham, 2004)

La reducción a la construcción elemental implica una visión de la geometría más allá de un momento histórico, la geometría en sus formas arquetípicas al ser el resultado de un lenguaje fisiológico primigenio el dibujo se vuelve ese espacio intersticial entre la idea y su acción sobre lo físico. Lo que interesa a Abraham es el reconocimiento de las relaciones geométricas específicas para su fabricación en esto consiste el proceso de de-composición y la re-clasificación. 
Hay una precisión increíble. El hermoso misterio de la arquitectura tiene sus raíces en la precisión de cómo poner una piedra sobre la otra. No es la piedra en sí; es el corte entre las piedras, la costura. La precisión del énfasis es el principio de estructura "cómo se unen o cómo se divorcian" (Abraham, 2004). El ejercicio ritual del re-dibujo, presente desde la tradición de la tratadística implica comprender sus procesos constructivos, de los edificios, la identificación de sus posibles relaciones y la fabricación de modelos a través las posibles proposiciones geométricas. Esto como un camino para de-construir el referente histórico, desprenderlo de su proposición simbólica inicial y realizar una traducción de la proposición en una maqueta. Este ejercicio revela la intención de ir al origen propio de la relación geométrica y reordenarla, imaginar otras disposiciones y otras materialidades. De esta forma "La Casa para el guardabosques" en la De-composición de sus partes constructivas, a través de la separación de sus capas, hace posible ver las posibilidades de su estructura portante, la cúpula desaparece y en su lugar vemos el cruce de cuatro vigas cruzadas de alma constante formados arcos, una idea antigua construida con las posibilidades del hormigón. 

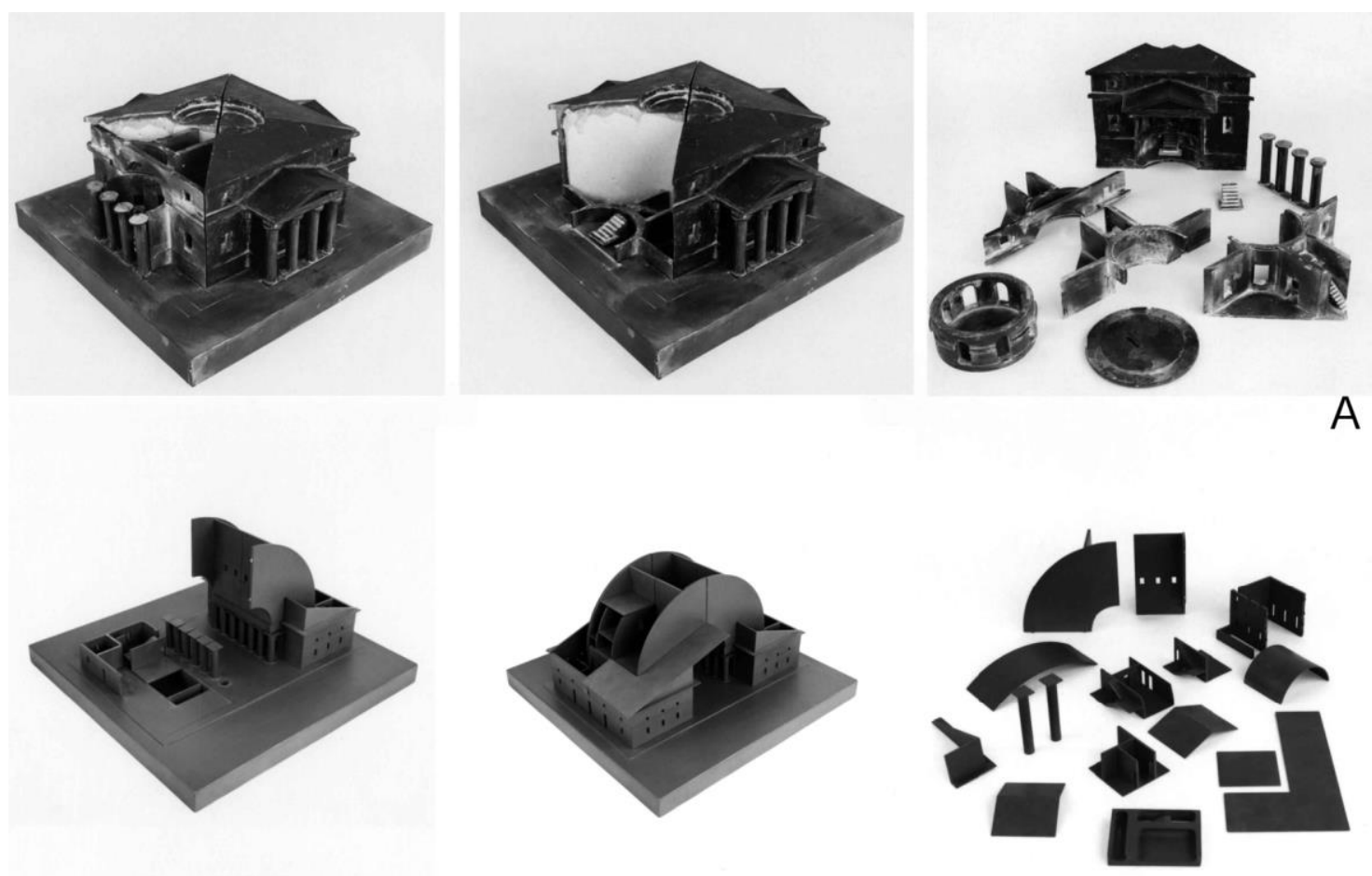

B
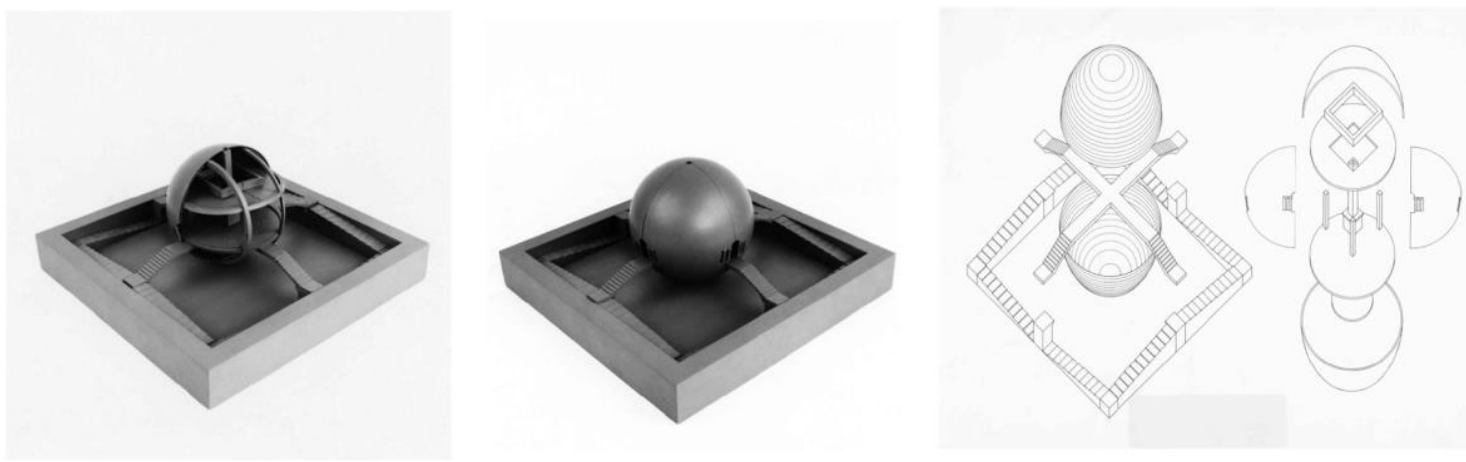

\section{ANÁLISIS DE LEDOUX}

1979-80

C

Columna

O̊ Capitel

.0 Frontón

« ํํㄹ Escaleras

월 Puente

¿

है 흔 Rotonda (espacio Interior)

岌 Curvilinea (Forma)

Fig. 4. El Análisis de Ledoux. Fuente: Archivo digital Cooper Union. 


\section{El proyecto de bloque - Anthony Candido}

El siguiente ejercicio expuesto en el libro es producido por Anthony Candido. Este arquitecto propone una exploración alrededor de una búsqueda como pintor. Candido en esta época estaba desarrollando pinturas de naturaleza muerta utilizando como tema su propia mesa de trabajo, estas pinturas trabajan a partir de caballetes sobre los cuales se colocan botellas, latas, tubos de pintura y herramientas. Pintar sobre cómo se pinta o con qué se pinta, los utensilios de trabajo como tema de trabajo.

"Lo que comenzó como un estudio y se convirtió en un viaje hacia lo desconocido. Sin proyecto designa una aventura inesperada que se me abrió, una que planteó muchas preguntas. La cuestión académica del realismo o la abstracción no tenía importancia. Estas cuestiones no ayudaron en nada a resolver, en términos de pintura, la profunda cuestión visual de la mente a la que me enfrentaba en mi mesa de pintor."(Candido, 1988a: 22)

Esta experiencia de fabricación contemplación a través de la construcción de bloques en papel Strathmore se propuso a través de 3 categorías, base, cloques y soporte. La base, el primer campo de trabajo, estaba tipificada con medidas, los bloques modulares podían tener cualquier tamaño, pero tenían que estar construidas con doble hoja de papel Strathmore y por último el soporte con el objetivo de poner la tabla y los módulos a una buena altura de observación, estos también construidos con papel Strathmore. La investigación se dedica al estudio de las relaciones de espacio creadas por los bloques (Candido,1988b).

El ejercicio se desarrolla a escala 1:1, presentando el dibujo y el modelo en la misma dimensión. Se hacen dibujos de diferente tipo, los primeros a mano alzada para luego pasar a limpio en tinta con las dimensiones y texturas precisas utilizando plantas, alzados y cortes, utilizando distintos tipos de línea para representar la cercanía del objeto al observador. Se pueden fabricar bloques representando distintos materiales. También se sugiere utilizar en lugar de la base de papel Strathmore una base de arena.

Este ejercicio propone la propia fabricación, la materialidad como tema de exploración, un recurso que varía los límites de lo artístico para generar una abertura, lo que es descrito por Candido como un viaje a lo desconocido que diluye el borde entre la abstracción y el realismo. Este proceso a la vez tiene como finalidad enfocarse en la fabricación de la construcción del modelo, las posibles configuraciones a través del dibujo a mano alzada y su dibujo final detallado de acuerdo con el lenguaje arquitectónico de la planta, el corte y el alzado. La precisión en las instrucciones del ejercicio deja un margen de variación en las dimensiones modulares de los bloques y en la materialidad representada. Hay que anotar que en el contexto del ejercicio 1979-80, este tipo de exploraciones de dilución del límite y abertura en la definición del objeto artístico fueron un tema común, explorando definiciones del arte como arte minimal, el arte conceptual o el arte de la idea (Lippard, 2004). También, el significativo hecho de que el objeto representado tenga similitud con un andamio de construcción nos habla de un material fundamental para los procesos constructivos de la arquitectura y comúnmente olvidado dejado de lado debido a su transitoriedad. Al igual que las formaletas, los andamios desaparecen de la obra una vez se ha concluido. 

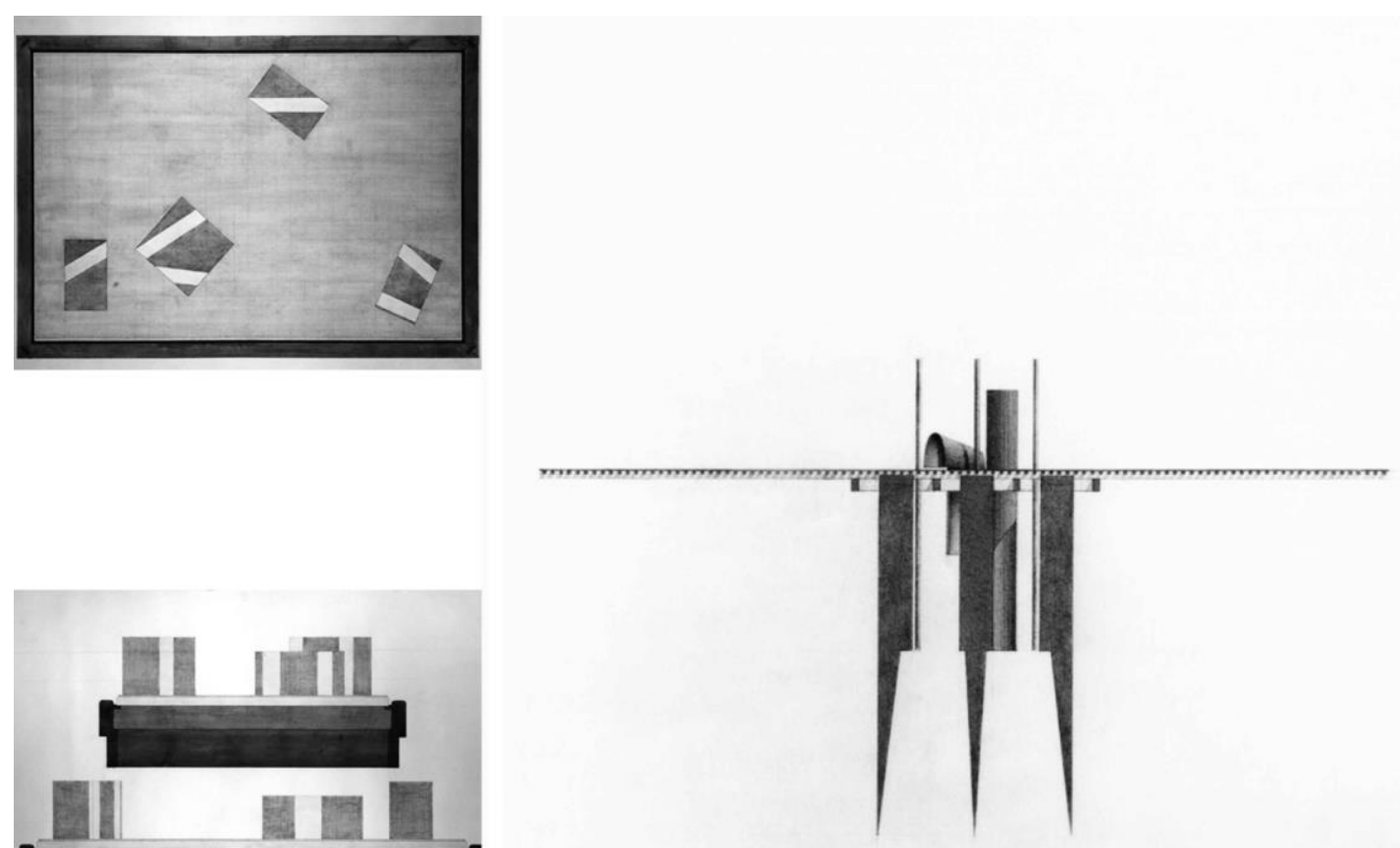

A

B
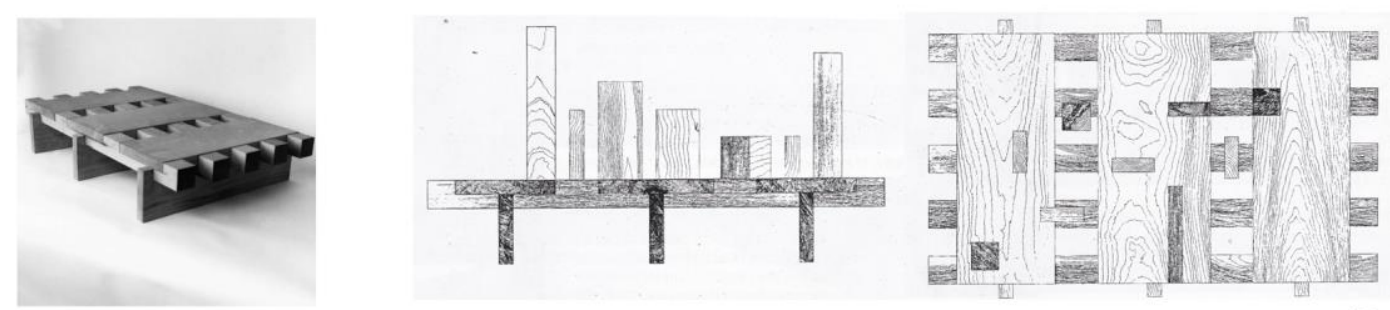

C

PROYECTO DE BLOQUE

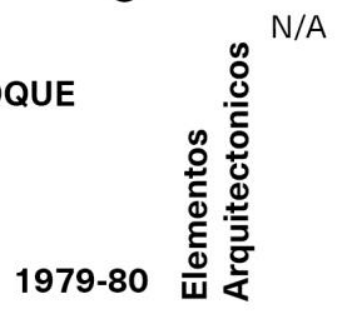

D

Fig. 5. El proyecto del Bloque. Fuente: Olsen y Prince - Archivo Digital Cooper Union. Naturaleza Muerta. Fuente: Ana Isabel Díez. 


\section{El puente - Anthony Candido y Chester Wisniewski}

El siguiente ejercicio está directamente relacionado con el tema de la estructura, la relación entre los elementos empleados y su comportamiento estructural. Las fuerzas sometidas encuentran un desarrollo formal y compositivo. La carga es vista como un componente visual integral y puede ser usado para completar la construcción del puente (Candido, 1988a: 22) las consideraciones críticas del puente incluyen las relaciones estéticas y proporcionales de todos los componentes. Todo esto para lograr una estructura inteligente en su construcción y uso de los materiales.

Las fases del ejercicio presentan 3 variaciones, el primero está planteado a escala real y tiene que sostener el peso de un ladrillo, el segundo debe contemplar un uso peatonal y el tercero un uso peatonal cubierto, los materiales incluyen madera, pegante, tornillos y tuercas. En todas las fases se dan instrucciones precisas sobre medidas, articulación del puente en los estribos y su enfoque. En la fase dos se habla de estudios de axialidad a través de la longitud del puente y sus intersecciones perpendiculares y horizontales con el centro. En el último ejercicio la cubierta se incorpora como un potencial volumétrico y estructural y se enfatiza en temas como la escala tema que se hace implícito en el cambio de escala de la fase 1 a la fase 2. Este ejercicio enfatiza en la forma como un resultado de su comportamiento estructural a través del empleo de unas condiciones de diseño y un uso determinado. Los ejercicios presentados exponen una amplia variedad de respuestas expresadas en términos formales directamente relacionados con sus cualidades estructurales.

Este ejercicio tiene su fundamento en la introducción propuesta por Chester Wisnieski (1988), en la cual se define la arquitectura como "el arte, profesión o ciencia del diseño y la construcción de edificios". Para Wisnieski, la arquitectura no debe de ser confundida con la caligrafía de la arquitectura, los dibujos, modelos, dibujos e incluso la palabrería esotérica. En la música, señala Wisnieski, una partitura exquisitamente escrita no es música hasta que es ejecutada, en arquitectura una bella representación gráfica no es arquitectura hasta el momento en que se construye, esta idea difiere claramente de la postura de Abraham (2004) y su dibujo de anticipación: "No necesito el edificio para verificar la idea; el dibujo en sí es la declaración final. Construyo con mi lápiz, anticipando la estructura. La música no es melodía".

En la introducción a este ejercicio Wisnieski (1988) realiza fuertes afirmaciones en contra de los no-arquitectos que participan de la arquitectura, "Ios teóricos, críticos Ilamándolos narcisistas de humo arquitectónico, habladores simplistas y volubles de la arquitectura, honderos de metáforas indescifrables. Una cinta con la mayoría de las críticas de estudios arquitectónicos suena para mí como un curso literatura inglesa con una dosis constante de jerga arquitectónica como metáfora, declaración, estratificación, dogma, simbolismo". 

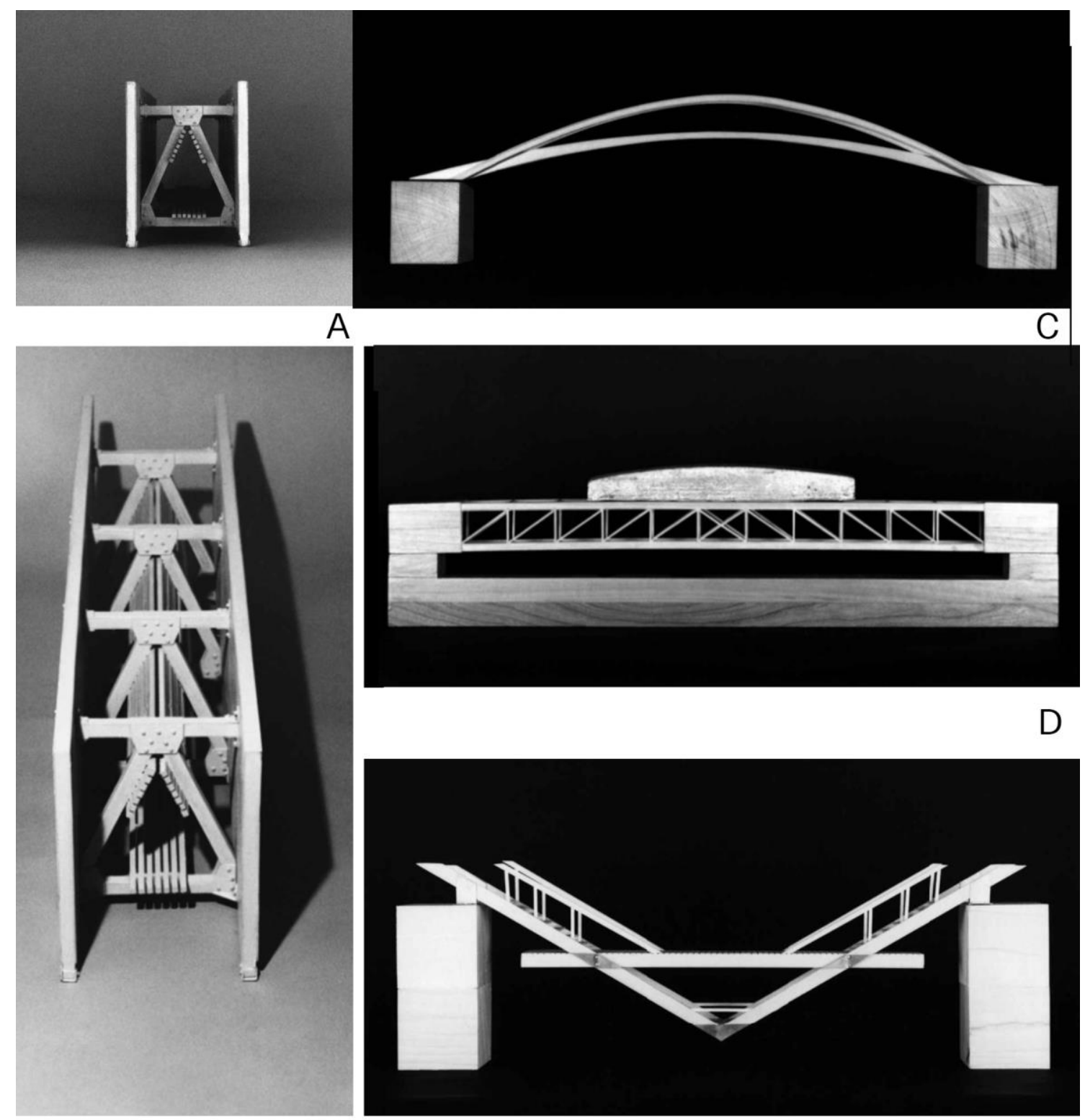

B

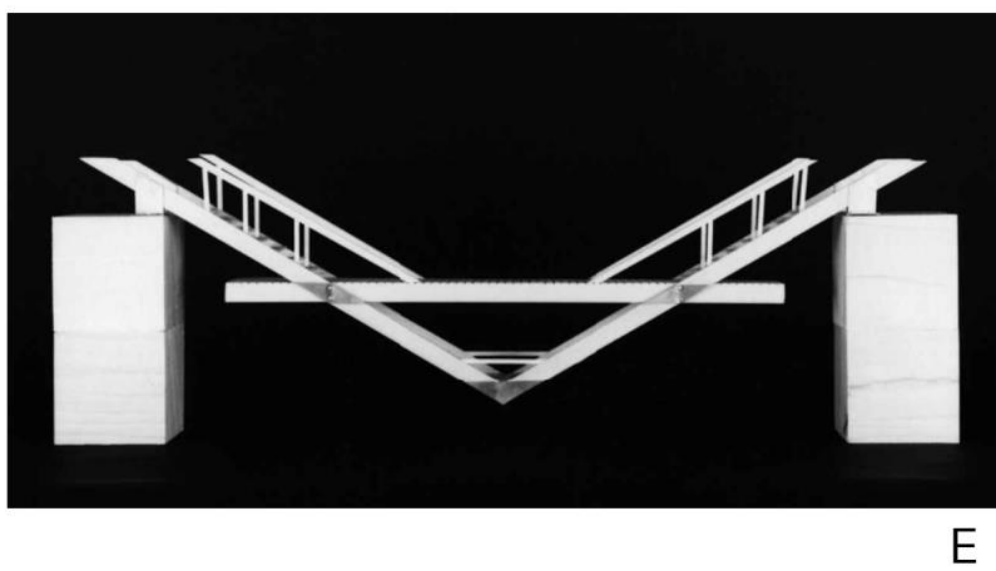

EL PUENTE

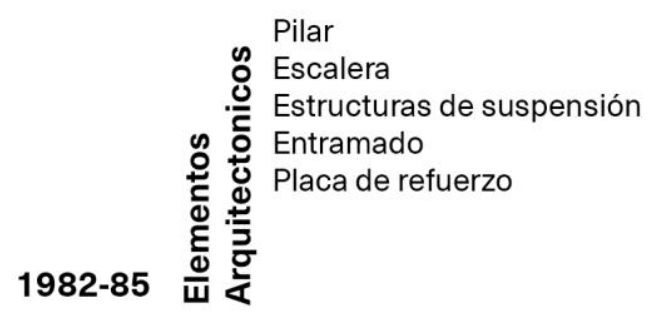

Peso

Escala

Relaciones Proporcionales

: Relaciones Estéticas

है Ejes

๑- Material

Fig. 6. El puente. Fuente: Archivo Digital Cooper Union. 


\section{La casa cartesiana: Raimund Abraham}

El siguiente ejercicio propuesto por Raimund Abraham lleva por título La Casa Cartesiana, este ejercicio planta como ubicación el cruce de los planos cartesianos, es la casa de un punto, que constituye el componente más elemental de la forma. El punto, explica Abraham, (1988: 24) “(...) es la base del topógrafo. El punto para medir todos los demás puntos a partir de ahora". La medida por otro lado sigue Abraham es el impulso esencial de la arquitectura. Al igual que el ejercicio del topógrafo, este ejercicio busca medir "con líneas ideales e invisibles el paisaje arcaico y amorfo. El "sitio" en su definición ontológica elemental es un punto, infinitamente pequeño, pero infinitamente preciso". Este ejercicio plantea una situación base, ortogonal, equilibrada y precisa, es la condición inicial para el ejercicio.

Un concepto presente en la obra de Abraham aplicable a la concepción de este ejercicio es la colisión o interferencia. Para Abraham la interferencia es la quintaesencia del acto arquitectónico, antitético a cualquier forma de estética o especulación histórica. El proceso de diseño es entonces "un acto posterior cuyo propósito es reconciliar y armonizar las consecuencias del choque inicial”(Abraham,1996: 219).

Para Abraham, la interferencia y la conformación se ejemplifican desde el acto mismo de dibujar como una transposición del texto escrito en un edificio construido. Para Abraham es posible hacer una taxonomía de la colisión en la arquitectura a partir de sus proyectos, la colisión del cuerpo con la arquitectura, la colisión de un objeto con la arquitectura, la colisión de la arquitectura con la luz, la colisión de la arquitectura con el paisaje. Este choque es llevado incluso al acto violento y traumático de la violación. Abraham afirma que para construir algo se debe violar el sitio. Los indios solo construyen tipos o construyen estructuras permanentes de piedra en la roca y nunca violan la tierra. La reconciliación para Abraham consiste en crear un nuevo equilibrio por medio de las condiciones formales. El equilibrio en el que ha intervenido y perturbado debe reconciliarse. Ese es realmente el papel de la arquitectura.

La primera fase del ejercicio tiene como finalidad concebir una proposición geométrica a un modelo físico, este modelo físico debe traducirse en un conjunto de componentes arquitectónicos este sería un primer momento de choque. El segundo momento de choque se da al llevar la composición arquitectónica idealizada al sitio. Un momento descrito como "una confrontación y síntesis de la composición principal con un programa de metáforas”(Abraham,1988: 2).

El termino de metáfora es comúnmente utilizado para describir la obra de Abraham, los ejercicios entregados no responden a proyectos resueltos, su intención no es otra que expresar a través de medios arquitectónicos, una realidad determinada, una proposición. Estos ensayos espaciales introducen a los estudiantes a las posibilidades del espacio arquitectónico manejado a través de formas arquitectónicas reconocibles. A través de su localización y aislamiento se crean imágenes de algo que todavía no se ha resuelto. Reconocimiento de la presencia del fragmento como un motor de trabajo para constituir el ejercicio. Como una metáfora, se completa en la mente del lector. En el archivo de la Cooper Union, encontramos una descripción más detallada de uno de los ejercicios: “EI 
espacio cartesiano está animado por la consideración de un espejo virtual e un ángulo de $45^{\circ}$ a través del centro vacío. Tres elementos: un cono, una esfera y un cubo se colocan en el sitio y se reflejan a través del espejo, tejiéndose y definiendo el sitio como un punto de transformación en una extensión ilimitada del espacio. El Proyecto es una huella de la desfiguración de estos objetos cartesianos"(Hofer, 2019). 

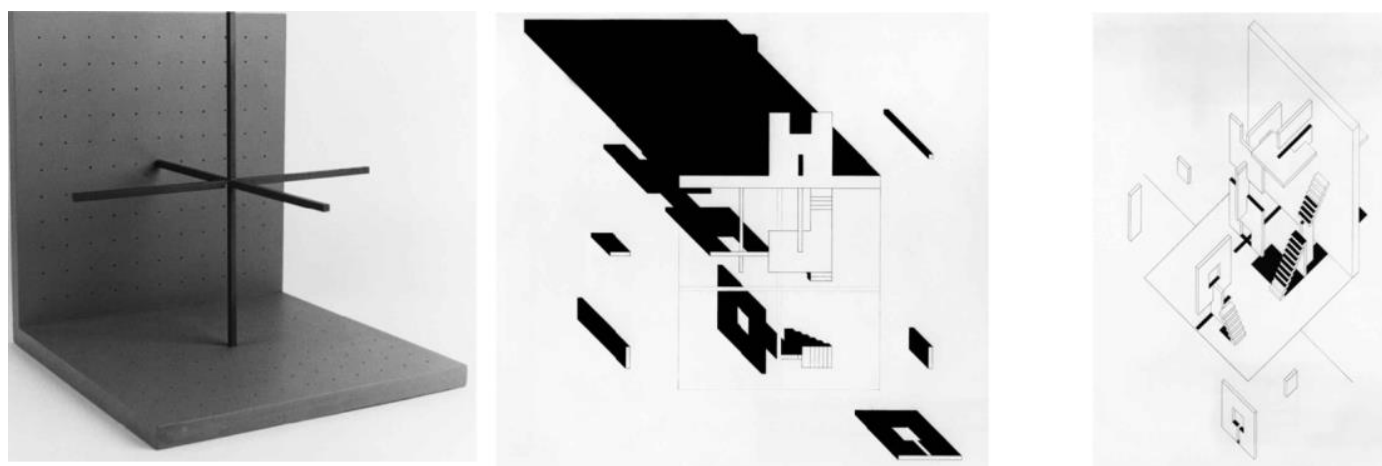

A
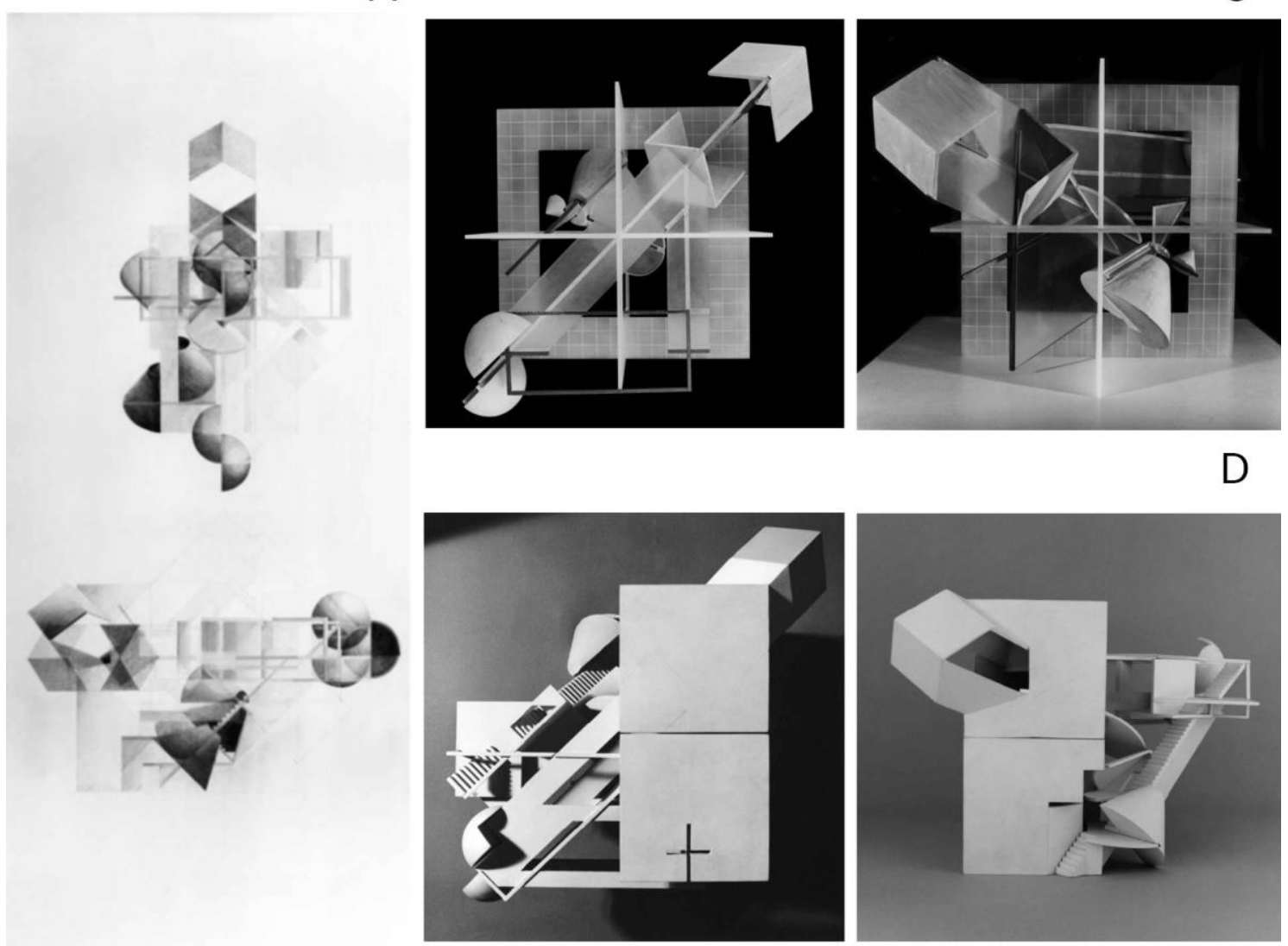

B

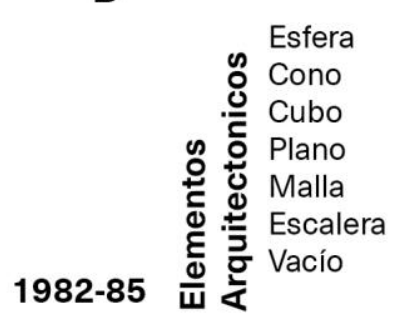

Sitio

Traducción

Clasificación

Intervención

Confrontación

đ? Síntesis

E Metáfora

E

\section{EL PUENTE}

Fig. 7. La Casa Cartesiana. Fuente: Archivo Digital Cooper Union. 


\section{Architectonics - Elizabeth Diller}

De toda esta serie de propuestas para el curso Architectonics, las Pruebas-problemas planteadas por Elizabeth Diller (1988) son las que más se separan de un marco geométrico preestablecido, no hay una retícula evidente, ni elementos modulares. La forma responde a un problema específico, el análisis y la propuesta de una forma móvil. La escala es total 1:1 aunque se deja espacio a considerar una escala indeterminada. Los temas planteados: un arco, una bisagra y una balanza; formas cambiantes cuya esencia radica en el movimiento. Cada pieza explica un concepto aplicable a la arquitectura, son exploraciones fuera del marco disciplinar que tienen como objetivo pensar otras posibilidades para el desarrollo de la forma. La tensión y la compresión, un rango angular, un rango de carga son conceptos que están presentes en la arquitectura, y condicionan la percepción del espacio.

Los dibujos expresan el material sometido a distintas fuerzas, Los elementos se disponen en función del conjunto, cada uno constituye un eslabón específico para que el sistema funcione y se compruebe. El primer ejercicio dedicado a un arco de tiro es titulado "La viga," (Fig. 8) parece un comentario sobre los ejercicios de El Puente de Candido y Wisniewski, ¿Cómo enseñar un concepto estructural sin emplear una estructura arquitectónica? y consiste en un análisis grafico secuencial de los diferentes momentos de compresión y tensión a través de un arco y su cuerda.

En "La Conexión, un estudio de estasis y animación" (Fig. 8) el dibujo presentado recuerda una columna vertebral, cada vertebra es un corte sucesivo del objeto en tensión en el momento de 90 grados, en las fotos se aprecia el detalle en los amarres en acero, y las cavidades de la madera. El dibujo de "Soporte de Esquina en Balance con Punto de Apoyo Cambiante" (Fig. 8) recuerda el ballet mecánico de Oskar Schlemmer, donde cada elemento describe una trayectoria y un movimiento, un antecesor de los móviles de Calder que a través de la localización del fulcro de la carga y los esfuerzos proporcionales ya que el ejercicio exige además ser un instrumento de medida.

Al igual que en el caso de los ejercicios del puente, hay una nota de epilogo escrita por Elizabeth Diller. A diferencia que, en el caso de Wisniewski, esta nota no plantea afirmaciones sobre lo que es la arquitectura, sino una pregunta: ¿Por qué la condición de equilibrio es identificada con la cordura? Ciertamente, la cultura, en su intolerancia a lo excéntrico y lo irresuelto, se ha apropiado de la simetría, la más simple de todas las ecuaciones, como imagen de estabilidad y, por tanto, de poder. La "a"-simetría y el “des"equilibrio son por inflexión, aberrantes. Solo se nombran los ideales. La vertical y la verdad son sinónimos. Ser oblicuo es desviarse tanto de la sinceridad como de la verticalidad. Sin embargo, una desviación que llega a la horizontal restaura la verdad; ser honesto es estar "al nivel". Los ideales sociales y espaciales son compartidos.

El lenguaje es la primera infiltración de la costumbre y debe ser rápidamente subvertida en el estudio de la arquitectura. Pues, ¿no es la sesgada vertical de echo un radio convergiendo con otros, así como la horizontal es el tortuoso, doblarse y cerrarse lentamente 
sobre sí mismo? ¿No es el equilibrio simplemente un evento? una momentánea resolución de las fuerzas, como la cordura es sólo un incidente dentro del alcance de la mente. (Diller, 1988). 

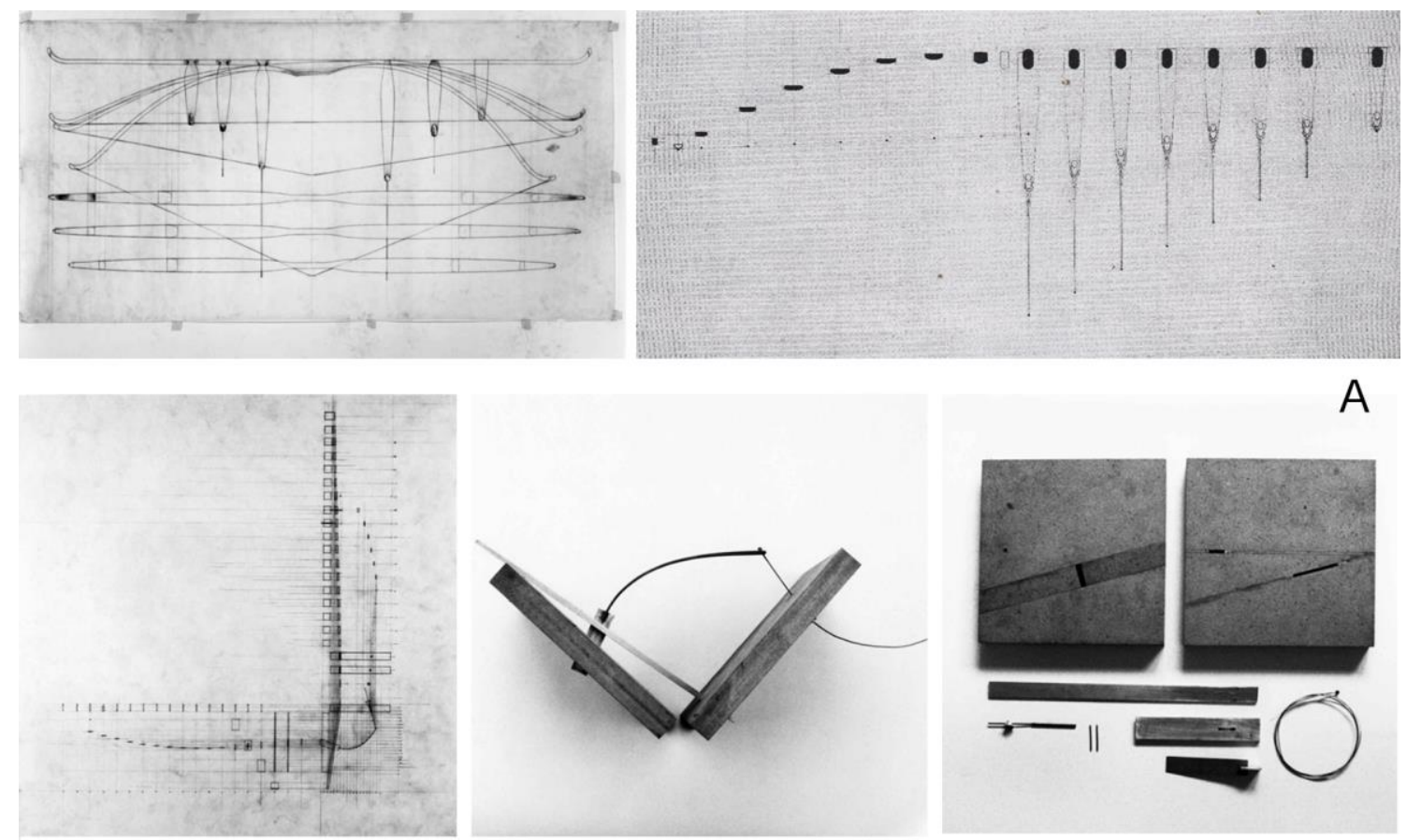

A

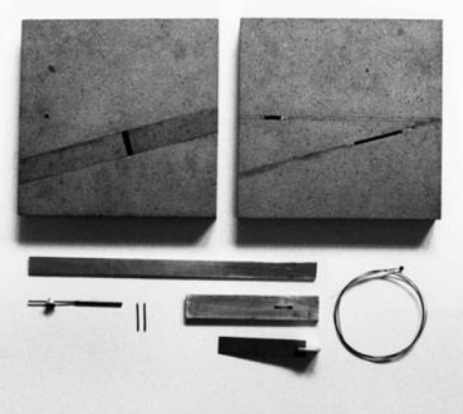

B
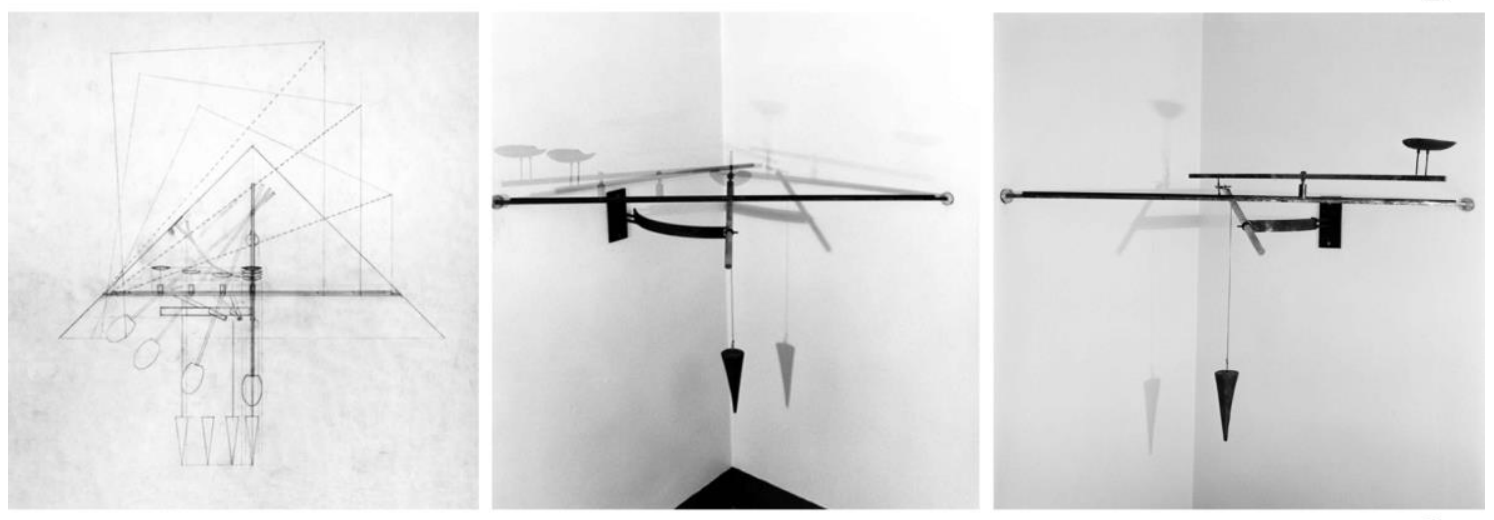

C

LA VIGA

LA CONEXIÓN

\section{EL BALANCE}

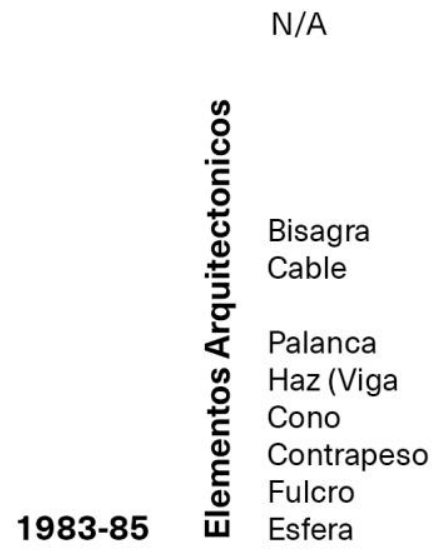

Fig.8. La viga. La conexión. El balance. Fuente: Archivo Digital Cooper Union.
Tensión Superficial

Compresión

Presión

Arco (Arma)

Equilibrio

Presión)

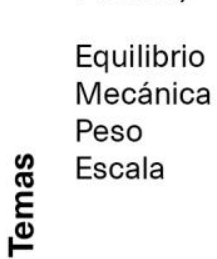

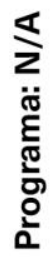


La serie de ejercicios planteados por Elizabeth Diller son subversivos en múltiples niveles. Para comenzar, son artefactos de diseño en el sentido de que involucran un uso determinado a diferencia de los ejercicios como la malla de los nueve, el puente o la casa cartesiana, aparece la escalera como un punto de referencia que nos habla puntualmente de elementos de arquitectura. La escala se considera como un recurso indeterminado en comparación a su tamaño actual que es objetual, y con la escala de una herramienta manual. La escala así mismo, es algo relativo, es posible relacionar los dibujos secuenciales con posibles estructuras arquitectónicas. Los cortes sucesivos, visualizan articulaciones, repeticiones, y progresiones, crean una notación que describe su mecánica. La función de estos ejercicios es el análisis, y cada uno funciona en la medida de que describa una lectura del movimiento, más que cumplir una función directa, es importante la huella que deja ese proceso en sus diferentes estados su forma se justifica en cuanto es un testigo, y en palabras de Diller estudia la reciprocidad entre lo visual y las fuerzas físicas.

La geometría aparece de forma marcada en cada uno de los ejercicios, dos cuadrados, una línea, círculos, un cuarto de circunferencia, media circunferencia, sin embargo, hay otros elementos que no se identifican con una forma básica, su forma es el resultado de la prueba y de la acción, resultado de una lógica puesta a prueba en la resolución de un problema determinado. En lugar del cartón Strathmore, o la madera, los materiales que se emplean son platinas de acero, dobladas, perforadas y cortadas, convertidas en rieles. Cables de amarre, pernos, remaches, varillas bolsas de tela. Hay un especial detalle en las uniones de los elementos, ya sean estos atornillados soldados o encajados, el resultado evoca una imaginería medieval.

El enfoque conceptual de Elizabeth Diller hace una alusión directa a la arquitectura, no a través de sus formas más características sino de su lenguaje; conceptos como compresión, presión, peso, contrapeso, equilibrio o mecánica aparecen de forma literal el fin mismo del ejercicio su propia comprobación y posible adaptación a través de una escala indeterminada, son objetos en potencia, contienen la literalidad de un fenómeno y así mismo se prestan para una futura aplicación. Estos mecanismos móviles son paralelos a la instalación Sentinel - Civic Plots de 1984. Ana Morcillo (2015) en su tesis de doctorado señala que esta instalación no tuvo mucho impacto en el medio artístico, sin embargo, en el medio arquitectónico contó con una muy buena de reseña de Keneth Frampton y Michael Kagan (1985) quienes describieron esta pieza como si se tratara de uno de los croquis de máquinas salidas de la imaginación de Da Vinci, cuatro siglos antes. Dimendberg (2013) señala dos influencias que conectan esta pieza con la Cooper Union, la primera a partir de lo que se describe como surrealismo medieval de Hejduk, caracterizado por el antropomorfismo en los edificios y las piezas y la segunda se relaciona directamente con los ejercicios de Architectonics. 


\section{Conclusiones}

La malla de los nueve desapareció de las aulas de la Cooper Union a mitades de los años 80 se presentaron adaptaciones en numerosas universidades, pero aparentemente sin el contexto disciplinar original (McNeur, 1983) convirtiéndola en una réplica irreflexiva. En la última década se han presentado varios textos que interpretan diversos aspectos de la malla (Love,2003; Páez, 2015; Estrella,2020). En el año 2016, en Harvard, se realiza la exposición 9SG: The Production of an Architectural Idea (Santos, 2016) a través de la cual se rinde homenaje a la malla de los nueve y al arquitecto John Hejduk en el quinceavo aniversario de su muerte. Esta exposición pone sobre la mesa temas como la indeterminación e irresolución del proyecto. A través de la malla, la arquitectura se convirtió en un lenguaje a aprender, en lugar de un problema funcional a resolver. Esto da cuenta de la vigencia de este problema como una introducción clásica al aprendizaje de la arquitectura.

Jose Aragüez (2015) en su reseña para el proyecto de Beatriz Colomina, Radical-Pedagogies reseña este periodo como una época en que se mostró una fuerte influencia del movimiento moderno. Aragüez indica que después de la exposición del MOMA, se dio un profundo interés en la diversificación disciplinaria, esto se evidencia en el libro publicado en el enfoque que tuvo el curso Architectonics, que representa un impulso renovado para mirar practicas creativas no arquitectónicas, distintas a la pintura modernista. Sin embargo, desde la mirada de Aragüez, está interesada por explorar esta doble tensión entre lo disciplinar y lo no disciplinar, entre el lenguaje arquitectónico y el aprendizaje de estructuras procedimentales que respaldan otras prácticas creativas.

En el caso de los proyectos dirigidos por Abraham, Candido y Diller desaparece el marco estable y simetrico creado por la malla, sin embargo, hay una interpretación de la estructura como forma de organización. Candido, por ejemplo, basa su ejercicio en el estudio de los bloques modulares, Abraham en un punto referencial cartesiano y Diller cuestiona la estabilidad estructural estudiando cualidades físicas para producir estructuras dinámicas. Wisniewski es quizás el que se mantiene en la línea más tradicional del grupo basando su ejercicio en la construcción de puentes que pone a prueba a través de cargas reales. Cada interpretación de la estructura y de la fabricación de la misma define un vocabulario formal propio, diversificando los elementos de cada ejercicio. De esta forma el lenguaje disciplinar de la arquitectura, entendido como un hecho interdisciplinar, está en constante proceso de revisión, expansión y subversión o crítica aun cuando mantiene principios compositivos fundamentales que se repiten a lo largo de la historia, y como encuentra Abraham se vuelven arquetípicos, estos principios y sus formas de organización se nutren del contexto cultural del ejercicio.

Esto nos lleva a que aun cuando no existe un programa explicito en ninguno de los proyectos, en todos genera un programa definido por las condiciones y las limitaciones establecidas. En algunos de estos ejercicios se hace explicito el concepto de la metáfora, es el caso de la malla de los nueve cuadrados y la propuesta de Raimund Abraham para La Casa Cartesiana. La metáfora que de acuerdo con McNeur (1985) tendría origen en un 
suceso significativo del estudiante lo que lo llevaría a construir un monumento a la memoria. En el caso de Abraham, como se puede observar en el archivo de la Cooper Union, reaparece la metáfora como eje para el ejercicio de Architectonics, algunos ejemplos son: Casa para La Contemplación (1987), la Casa Para La Anticipación (1997), Una Casa para un Hombre Errante (1999) o una casa para Karlheinz Stockhauser (2001). En el caso del currículum para la clase Architectonics en el año 2000, definido como "el Problema del Cubo", se establece un programa de recursos conceptuales que se toman como punto de partida "para comprender el significado de las relaciones compositivas, (que) el estudiante debe correlacionar (...) con el ejercicio. (...) este programa del edificio es escogido de acuerdo a implicancias formales y/o posiciones filosóficas en diversas culturas y estiIos" (Abraham et al., 1999:2), estos son algunos de los ejemplos:

Escala/ Proximidad Sam Sebastian de Piero della Francesca

Punto de Vista/ Líneas Nasca, Perú

Raíces Radicales/Originario vanguardia Rusa Mlevich Rodchenko

IndividuaV Social Tatlin Rodchenko, El Lissitzky

Gravedad/Ausencia como significante de la presencia de Dios en el fresco de Padua de Giotto

La intención de este ejercicio es darle corporeidad a un concepto estético/filosófico a través de su translación al espacio arquitectónico, cada estudiante, en palabras de Abraham, confronta este programa y lo traduce en sus propios términos: "el programa tiene que ser tiene que ser traducido; tiene que ser desafiado por el ideal de la disciplina”. El estudiante interpreta el programa implícito presente en la arquitectura y que se relaciona con un ideal surgido de su experiencia concreta. Esta práctica desde los primeros semestres confronta la lectura funcional de un edificio empoderando la interpretación del programa implícito de la arquitectura y promoviendo lo que se desarrollará en los semestres posteriores que Lewis y Diller definen como "la búsqueda de la invención en el programa, una redefinición del potencial del contrato social en las especulaciones arquitectónicas"(Lewis y Diller, 1988). Así, en la clase de Architectonics desaparece el programa como una condición explicita al ejercicio alentando la una elaboración propia de un programa subyacente, para esto se emplean las constantes propias de la disciplina dadas a través del lenguaje arquitectónico y se nutren de la traducción interdisciplinar.

“Creo en el contrato social por eso enseño. Creo que la Universidad es uno de los últimos lugares que protege y preserva la libertad, por eso la docencia es también un acto sociopolítico, entre otras cosas. Creo en los libros y en la palabra escrita, por eso fabrico obras con la esperanza de que queden registradas en libros. Soy pragmático y creo en llevar registros. Creo que registrar es dar testimonio. El libro que escribí, Víctimas es dar testimonio y recordar. Creo en la densidad de lo disperso. Creo en el lugar y el espíritu del lugar" (Hejduk,1985: página). 


\section{Referencias}

ABRAHAM, R. The Ledoux exercise. En: The Education of an Architect: Irwin S.Chanin School of Architecture of the Cooper Union. Nueva York, Editorial Rizzoli, 1988a. pp. 14-17. ISBN 0-478-0970-6

ABRAHAM, R. The cartesian house. En: The Education of an Architect: Irwin S.Chanin School of Architecture of the Cooper Union. New York, Editorial Rizzoli, 1988b, pp 24-31. ISBN 0-478-0970-6

ABRAHAM, R. The Reality of the unbuilt. En: [UN]Built. Viena, Springer Wien, 1996, pp. 110-113.

ABRAHAM, R., GERSTEN, D., WALTERMATH, J., WINES, S. 1st Year Architectonics, Academic Year 1998/99 The Student Work Collection. En: The Irwin S. Chanin School of Architecture, Nueva York, 1999. Disponible en: https://archswc.cooper.edu/Browse/projects/facet/entity_facet/id/5

ABRAHAM. R. Raimund Abraham by Carlos Brillembourg. En: Boom, 77, 2001. Disponible en https://bombmagazine.org/articles/raimund-abraham/

ABRAHAM, R. A Converzation with Raimund Abraham with Gregory Zucker. En: Logos A Journal of modern society \& culture, 2004, 3(3) Disponible en: http://www.logosjournal.com/abraham.htm

ABRAHAM, R. Paper Planes, En: Pol Magazine, 02 (11), 2004, pp 106-114.

ALLEN, S. John Hejduk's Axonometric Degree Zero. En: Drawing Matter, 23/09/2019. Disponible en línea: https://drawingmatter.org/john-hejduks-axonometric-degree-zero/

ARAGÜEZ, J. John Hejduk, The Cooper Union School of Architecture. En: Radical Pedagogies, 2015. Disponible en línea: http://radical-pedagogies.com/search-cases/a16-cooper-union-school-architecture/

BORGES DE MENESES, R. D. La deconstrucción en Jacques Derrida: Qué es y qué no es como estrategia. En: Universitas Philosophica, 30(60), 2013, pp. 107-204. Disponible en línea: https://revistas.javeriana.edu.co/index.php/vniphilosophica/article/view/10788

CANDIDO, A. Bridge. En: The Education of an Architect: Irwin S. Chanin School of Architecture of the Cooper Union. Nueva York, Editorial Rizzoli, 1988a. pp. 20-23. ISBN 0-478-0970-6

CANDIDO, A. Block Project. En: The Education of an Architect: Irwin S.Chanin School of Architecture of the Cooper Union. Nueva York, Editorial Rizzoli, 1988b. pp. 8-19. ISBN 0-478-0970-6

CESARIANO, C. Pollione de Architecture, 1521.

COOPER UNION. Archivo Digital. Disponible en línea: https://archswc.cooper.edu/Browse/projects

CONSUEGRA, D. En busca del cuadrado. Bogotá, Editorial Universidad Nacional de Colombia, 1994, ISBN 978-958-17-0088-2

DELGADO BERROCAL, S. Le Corbusier y la construcción vertical del espacio estratificado: En: Le Corbusier. 50 años después. Congreso Internacional. Valencia 18-20 noviembre, 2015. Valencia, Editorial Universitat Politècnica de València. https://doi.org/10.4995/LC2015.2015.690

DILLER, E. Architectonics. En: The Education of an Architect: Irwin S.Chanin School of Architecture of the Cooper Union. Nueva York, Editorial Rizzoli, 1988. pp. 32-39. ISBN 0-478-0970-6

DIMENDBERG, E. Diller Scofidio + Renfro: Architecture after Images. Chicago, The University of Chicago Press, 2013. https://doi.org/10.7208/chicago/9780226008721.001.0001

DURAND. J.N.L. Compendio de lecciones de Arquitectura. Parte grafica de los cursos de arquitectura. Bogotá, Pronaos Editorial, 1805. ISBN 978-84-85941-00-1

ESTRELLA, L. Problema y ejemplo: Los nueve cuadrados y la transformación del edificio fundacional de la Cooper Union. En: Estudios del Hábitat, 18, 2020, pp. 2-3. https://doi.org/10.24215/24226483083

FRAMPTON, K., KAGAN, M. Nouvelles Directiosn De L’'Architecture Moderne, New York-París, Eleca Monitors, 1984. Citado en: DIMENDBERG, E. Diller Scofidio + Renfro: Architecture after Images. Chicago, The University of Chicago Press, 2013. 
HEJDUK, J. Mask of Medusa: Works 1947-1983. Nueva York, Rizzoli International Publications, 2009. ISBN 978-0847805679.Citado en: PÁEZ-CALVO, A. La malla de los nueve cuadrados: de la estrategia proyectual a la herramienta pedagógica. En: Iconofacto, 11(16), 2005. Medellín, Universidad Pontificia Bolivariana, pp. 40-55.

HEJDUK, J., HENDERSON, R. The Education of an Architect: Irwin S.Chanin School of Architecture of the Cooper Union. New York, Editorial Rizzoli, 1988. pp. 1-13. ISBN 0-478-0970-6

HEJDUK, J. (1992) 2010. El arquitecto que dibujaba ángeles: Entrevista con John Hejduk. Texto basado en la entrevista realizada en 1992 por David Shapiro, traducción Araceli Maira, Minerva, 14, Madrid, Círculo de Bellas Artes. ISSN: 1886-340X

HOFER. A. Abstract Cartesian House. The Student Work Collection. En: The Irwin S. Chanin School of Architecture. Nueva York, 2019. Disponible en: https://archswc.cooper.edu/Detail/objects/1877

LAUGIER, M.A. Essai sur l'Architecture, París, 1753

LEWIS, D., Diller, E. The Education of an Architect: Irwin S. Chanin School of Architecture of the Cooper Union. Ciudad, Editorial Rizzoli, 1988. pp. 7-9. ISBN 0-478-0970-6

LOVE, T. Kit-of-Parts Conceptualism: Abstracting Architecture in the American Academy. En: Architecture as Conceptual Art? Blurring Disciplinary Boundaries, 19 F/W, 2003, ISSN 1093-4421

LIPPARD, L. Intentos de Escapada. Seis Años: La desmaterializacion del objeto artístico de 1966 a 1972, Madrid, Akal, 2004. ISBN: 84-460-1175-1.

MARTIN, H. Cabaña Primitiva. En: Goujon, J. Architecture ou Art de bien bastir, 1553.

MARTíNEZ, G. La malla de los nueve. Conferencia dictada en la Universidad Católica de Colombia, febrero 10, 1997 Disponible en CENDOC (Centro de documentación del Cifar, Universidad Católica de Colombia).

MARTíNEZ, S. 9 cuadrados En: Revista de Arquitectura, 2(1), 2000, pp.2-3. Universidad Católica de Colombia. ISSN 1657-0308. Disponible en: https://revistadearquitectura.ucatolica.edu.co/article/view/965

MCNEUR, L. Nine Square Grid. En: The Student Work Collection. The Irwin S. Chanin School of Architecture. Nueva York. 1976-77. Disponible en: https://archswc.cooper.edu/Detail/objects/7294

McNeur, L. The Nine Square Grid. En: Section a 1983, 1(4), Montreal, 1983, pp.24-37. ISSN 0715-9781

MONEO, R. L’opera di John Hejduk ovvero la passione d'insegnare. En: Lotus International, 27, noviembre 1980, pp.56-81.

MORCILLO, A. Nueva York: La revitalización del espacio público a partir de 1950. Tesis Doctoral. 2015. Universidad Politécnica de Madrid. Disponible en: http://oa.upm.es/40570/

PAEZ, A. La malla de los nueve cuadrados: de la estrategia proyectual a la herramienta pedagógica. En: Iconofacto 11 (16), 2015, pp 40-55 Bogotá

RIVIUS, W. Vitruvius Teutsh, atribuida a Vigil Solis, 1948.

ROWE, C., SLUTSKY, R. Transparencia Literal y Fenomenal. En: Manierismo y arquitectura moderna yotros ensayos. Madrid, Editorial Gustavo Gili, 1980, pp. 155 -175. ISBN: 84-252-0723-1

RYKWERT, J. La Casa de Adán en el Paraíso. Barcelona, Gustavo Gili, 1999. 1a ed. On Adam's House in Paradise, 1974.

SØBERG, M. John Hejduk's Pursuit of an Architectural Ethos. En: Footprint, jan., 2012, pp. 113-128, Delft, ISSN 1875-1490. https://doi.org/10.7480/footprint.6.1-2.753

THOENES, D., Teoría de La Arquitectura. Del renacimiento a la actualidad. 2011, Madrid, Tashen. ISBN 9783-8365-3200-6

WISNIESKI, C., On Architecture. En: The Education of an Architect: Irwin S.Chanin School of Architecture of the Cooper Union. New York, Editorial Rizzoli, 1988, pp. 20-23. ISBN 0-478-0970-6 


\section{Bio}

Mauricio Pérez Fernández, Arquitecto de la Universidad Católica de Colombia, Magister en Historia y Teoría del Arte la Arquitectura y la Ciudad de la Universidad Nacional de Colombia, ha sido colaborador en proyectos de investigación en temas como patrimonio, patrones de la vivienda autoconstruida, arquitectura colectiva y el diseño diagramático. Su más reciente investigación indaga en torno a las posibilidades del diseño paramétrico y el cambio en las formas de proyectar que trae consigo la arquitectura digital. Ha sido docente e investigador de varias universidades en Bogotá y actualmente trabaja como profesor e investigador asociado en la Universidad La Gran Colombia. 
La educación de un arquitecto en primer año: La malla de los nueve cuadrados y Architectonics de la Cooper Union

Oscar Mauricio Pérez Fernández
Recibido: 10/09/2020

Aceptado: 11/06/2021

DOI: 10.14198/12.17697 